\title{
Vibration as an exercise modality: how it may work, and what its potential might be
}

\author{
Jörn Rittweger
}

Accepted: 13 November 2009/Published online: 12 December 2009

(C) Springer-Verlag 2009

\begin{abstract}
Whilst exposure to vibration is traditionally regarded as perilous, recent research has focussed on potential benefits. Here, the physical principles of forced oscillations are discussed in relation to vibration as an exercise modality. Acute physiological responses to isolated tendon and muscle vibration and to whole body vibration exercise are reviewed, as well as the training effects upon the musculature, bone mineral density and posture. Possible applications in sports and medicine are discussed. Evidence suggests that acute vibration exercise seems to elicit a specific warm-up effect, and that vibration training seems to improve muscle power, although the potential benefits over traditional forms of resistive exercise are still unclear. Vibration training also seems to improve balance in sub-populations prone to fall, such as frail elderly people. Moreover, literature suggests that vibration is beneficial to reduce chronic lower back pain and other types of pain. Other future indications are perceivable.
\end{abstract}

Communicated by Susan Ward.

\section{J. Rittweger ( $\square)$}

Institute of Aerospace Medicine,

German Aerospace Center,

Linder Höhe 1, Köln 51147, Germany

e-mail: joern.rittweger@dlr.de

J. Rittweger

Institute for Biomedical Research into Human Movement and Health (IRM), Manchester Metropolitan University,

Oxford Rd, Manchester M1 5GD, UK
Keywords Mechanical oscillation · Training ·

Rehabilitation · Physical medicine · Safety · ISO standard

\section{Nomenclature}

a Acceleration, $\mathrm{m} \mathrm{s}^{-2}$

$a_{\text {Peak }}$ Peak acceleration, i.e. largest acceleration within one vibration cycle. For sinusoidal oscillations given by $\omega^{2} A$ (Eq. 1), $\mathrm{m} \mathrm{s}^{-2}$

$a_{\mathrm{RMS}}$ Mean acceleration, i.e. average acceleration over an entire vibration cycle. For sinusoidal oscillations given by $a_{\text {Peak }} / \sqrt{ } 2$ (Eq. 2), $\mathrm{m} \mathrm{s}^{-2}$

A Amplitude of the oscillation. In other words, the displacement of the oscillating actuator is between $-A$ and $A, \mathrm{~m}$

BMD Bone mineral density

$D$ Damping factor, given by the ratio of the attenuation coefficient and $\omega_{0}$

EMG Electromyography

$f \quad$ Frequency of the oscillation, i.e. the number of vibratory cycles per unit time. Therefore, $1 / f$ gives the duration of a single cycle, $\mathrm{Hz}$, which is equivalent to $\mathrm{s}^{-1}$

g Gravitational acceleration on Earth, $9.81 \mathrm{~m} \mathrm{~s}^{-2}$

$k \quad$ Stiffness, i.e. the resistance to deformation, $\mathrm{N} / \mathrm{m}$

$m \quad$ Mass that is inert to acceleration as well as being accelerated by gravity, $\mathrm{kg}$

3.1415

$\omega \quad$ Angular frequency. $\omega$ is proportional to $\mathrm{f}$, as it is given by $2 \pi f, \mathrm{~Hz}$, which is equivalent to $\mathrm{s}^{-1}$

$\omega_{0} \quad$ Resonance frequency of the resonator, i.e. frequency at which mechanical energy will be accumulated, expressed as angular frequency, $\mathrm{Hz}$

$\omega_{\mathrm{A}} \quad$ Angular frequency of the actuator, $\mathrm{Hz}$ 


\section{Introduction}

A visit at the local gym will demonstrate how popular vibration exercise currently is, with numerous devices available for exercise and physical therapy. However, the notion that vibration can be beneficial is relatively new, as it has traditionally been regarded as only detrimental. That view originated from occupational exposure to vibration. In the neuronal sciences, by contrast, vibration is a standard tool of investigation (Hagbarth and Eklund 1969). It is therefore fair to say that studies of vibration effects have a long tradition.

Nevertheless, only few authors have postulated therapeutic effects by vibratory stimuli in the past. Among them, the first were Sanders (1936) and Whedon et al. (1949), who performed some studies on an oscillating bed, meant to counteract cardiovascular and musculoskeletal de-conditioning. Nazarov and Spivak (1985) were the first to apply vibration as a training modality for athletes. With some delay, this led to an emerging scientific interest in vibration as an exercise modality (Bosco et al. 1998a, b, 1999a, b, 2000; Issurin and Tenenbaum 1999; KerschanSchindl et al. 2001; Rittweger et al. 2000, 2002a), not least driven by companies who started to market commercial devices.

However, vibration exercise nowadays being broadly available to exercisers and patients, it seems that this exercise modality is still largely unknown to the scientific community, and there is currently no comprehensive review available on the topic to allow an in-depth understanding, which is the purpose of the current article. Two fascinating fields, however, will go more or less unmentioned, namely central nervous information processing of vibration, as it is too complex to be covered here, and the potential effects upon adipogenesis, for which the available evidence is still preliminary.

When being vibrated on a platform, most people report an unusual perception that is often compared to the ranging and banging of the feet during downhill skiing. This sensation is partly due to a movement illusion (see "Neurophysiological responses"), and there is also a perception of exertion, which is not explicable by metabolic rate (see Fig. 1). Vibration applied to the tendons during isometric contractions leads to an over-estimation of the force generated by $30 \%$ (Cafarelli and Kostka 1981), and, conversely, a $25 \%$ smaller than intended force is generated. Quite confusingly, the discrepancy between intended and actual force levels declines during prolonged contractions (Cafarelli and Layton-Wood 1986). The important question therefore is whether the current interest in vibration as an exercise modality is only due to unduly perceived exertion, or whether it can really constitute a physiological training stimulus.

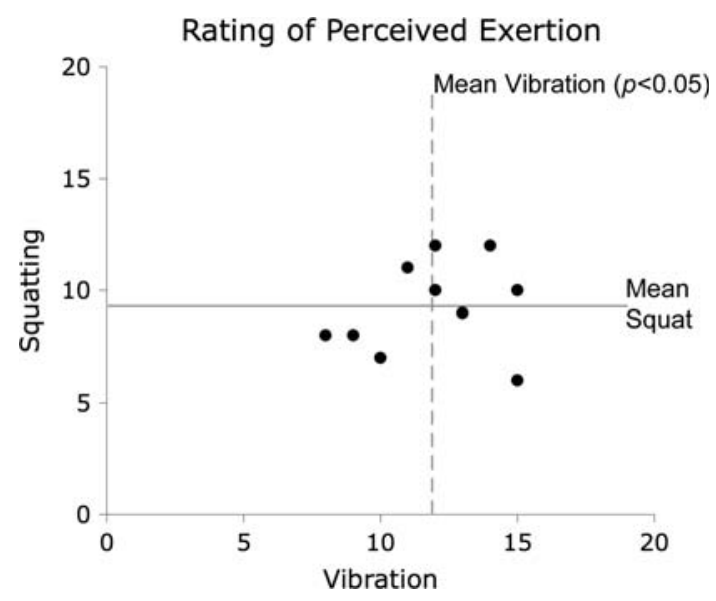

Fig. 1 Rating of perceived exertion (RPE) on a scale of 20 (Borg and Borg 1976) during either simple squatting exercise (ordinate) or whole body vibration exercise (abscissa) on a Galileo Fitness platform (Novotec Medical, Pforzheim, Germany). Both conditions were set up so that the metabolic rates were matched (squatting: $11.4 \mathrm{ml}$ $\mathrm{O}_{2} \mathrm{~kg}^{-1} \mathrm{~min}^{-1}$ (SD 0.7), vibration $10.7 \mathrm{ml} \mathrm{O}_{2} \mathrm{~kg}^{-1} \min ^{-1}$ (SD 1.0), $p=0.3$ ). By contrast, RPE was significantly greater in vibration (mean 11.9, SD 2.4, dashed line) than in squatting (mean 9.3, SD 2.1, solid line) exercise, suggesting that at perceived exertion is at least partly dominated by factors unrelated to metabolic rate. Interestingly, there seems to be no relationship between RPE values for vibration and squatting conditions, indicating that different people perceive both exercise modalities as differently exerting. Data are from an unpublished experiment by Rittweger \& Degens

\section{Physical principles}

Vibration is a mechanical oscillation, i.e. a periodic alteration of force, acceleration and displacement over time. Vibration exercise, in a physical sense, is a forced oscillation, where energy is transferred from an actuator (i.e. the vibration device) to a resonator (i.e. the human body, or parts of it). In most vibration exercise devices, these oscillations have sinusoidal shape, and they are therefore described by amplitude $A$, frequency $f$, and phase angle $\varphi$. Here and in the following $A$ denotes the mathematical amplitude, i.e. half the peak-to-peak amplitude. The angular frequency $\omega$ is given as $2 \pi f$. During vibration exercise, the human body is accelerated, which causes a reactive force by and within the human body. Importantly, the peak acceleration $\left(a_{\text {Peak }}\right)$ in sinusoidal oscillation is given by

$a_{\text {Peak }}=\omega^{2} A$.

Peak forces are potentially harmful to the body. On the other hand, forces also constitute a training stimulus. Therefore, $a_{\text {Peak }}$ values are important to consider. Another convention to quantify vibration exposure is by RMS (meaning root-mean square), which for sinusoidal oscillations relates to $a_{\text {Peak }}$ as

$a_{\mathrm{RMS}}=\frac{a_{\mathrm{Peak}}}{\sqrt{2}}$. 
The actuator: different device types

Vibration exercise is mostly practiced as whole body vibration, i.e. while standing on oscillating platforms. Among the different platforms, two different types of energy transfer have to be discerned. One type transfers vibration to both feet synchronously, whilst the second type operates in a side-alternating way, so that the right foot is lowest when the left foot is highest (and vice versa, Fig. 2a). It has been argued that side-alternating vibration would evoke rotational movements around the hip and lumbo-sacral joints (Rittweger et al. 2001). This movement introduces an additional degree of freedom (see next section) and, accordingly, whole-body mechanical impedance is smaller in side-alternating than in synchronous whole body vibration (Abercromby et al. 2007b). It should be mentioned here that attempts have been made to develop a third device type with randomly varying movements in the horizontal and vertical plane. However, there are only very few studies on this random vibration system, and due to technical difficulties only vibration frequencies well below $10 \mathrm{~Hz}$ have been tested so far.

Finally, vibrating dumbbells have been developed for upper-body exercise, which can be suspended and combined with weight stacks (Cardinale and Rittweger 2006). Their mechanical action on the human body will depend on the specific set-up. However, when controlling for the

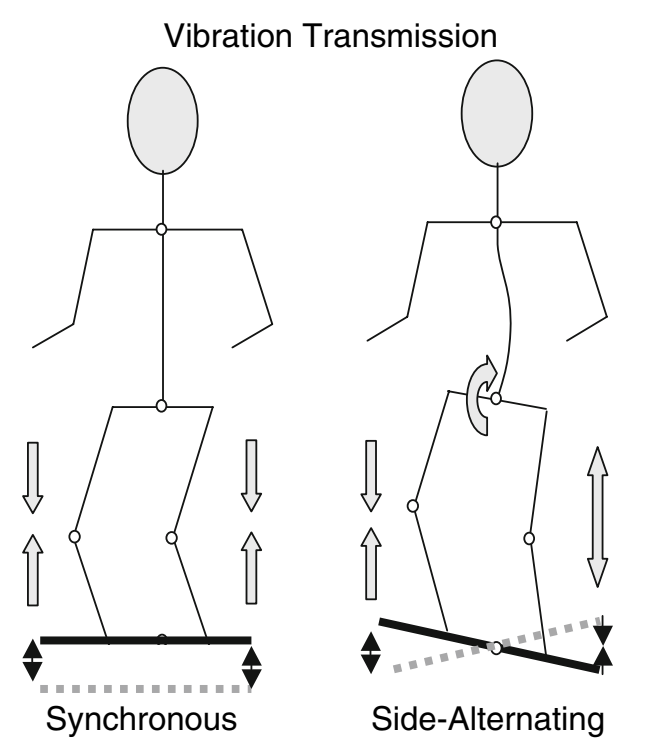

Fig. 2 Illustration of the two principle modes of vibration transmission in whole body vibration exercise. In the synchronous mode, both legs extend and stretch at the same time, and a purely linear acceleration is directed to the trunk. In the side-alternating mode, conversely, the right and left leg operate anti-phase, which introduces a rotary component to the lumbar spine and therefore is expected to reduce vibration transmission to the trunk. Evidence suggests, that greater $a_{\text {Peak }}$ levels can be tolerated in the side-alternating as opposed to the synchronous vibration mode (Abercromby et al. 2007b) effective stimulatory parameters (force, velocity, energy), the physiological responses to these devices should resemble the response to platform devices.

Devices also differ by way of energy generation. Whilst some operate by direct mechanical transmission (e.g. Galileo $\left.^{\circledR}\right)$, some rely upon electromagnetic transmission, and most available machines are based on oscillating massspring systems (e.g. PowerPlate ${ }^{\circledR}$ or FitVibe ${ }^{\circledR}$ ). As one would expect, not all systems perform equally well (see http://www.massamagra.com/pedane-vibranti/ recensioni.htm), and scientists should convince themselves, e.g. by using accelerometers, of an accurate setting.

The resonator: importance of stiffness, damping and posture

What happens to the body when being vibrated? As a first approximation, consider a rigid body with mass $m$. When the attachment of such a rigid body to the vibration device is firm, then it will simply follow the sinusoidal trajectory imposed by the actuator. The force applied is then determined by the acceleration of $m$. On whole-body platforms, however, there is no firm attachment and the only downward force acting on the body is gravity (Yue and Mester 2002). As a consequence, the rigid body will lose contact and become air-bound when the acceleration of the platform is smaller than $-1 g$ (see Fig. 3). Practically, this is the reason why people's feet sometimes skid on the vibration plate. Moreover, as can also be seen from Fig. 3, a collision with the platform will occur towards the end of the air borne phase. This leads to the generation of impact forces. Spectral analysis will interpret such impacts as frequencies greater than the vibration frequency, some of which will impose as harmonics (i.e. spectral power at $2 f$, $3 f, 4 f$ etc.). Conversely, being air-bound can also lead to missing out one or several cycles of the vibration platform, and thus generate sub-harmonic frequencies (i.e. $f / 2, f / 3$, $f / 4)$ in the vibrated object. Hence, firm stance on the force plate must be achieved in order to ascertain well-defined vibration parameters.

Obviously, however, the human body is not a rigid body, and muscles and tendons act as spring-like elements that store and release mechanical energy. In such a spring-mass system, compression occurs during the vibration upstroke, and expansion during the down stroke. As a consequence, the displacement is smaller at the body's centre of mass than at the platform level. Together, the stiffness and mass determine the natural frequency $\left(\omega_{0}\right)$ of such a system. More precisely, $\omega_{0}=\sqrt{k / m}$, where $k$ is stiffness and $m$ mass. Obviously, adjustment of $\omega_{0}$ must be through alteration of $k$, as $m$ cannot be changed.

It is important to understand that such a mass-spring resonator can accumulate mechanical energy, namely when 
Fig. 3 Demonstration of the behaviour of a rigid body that is attached to a vibration platform by gravity only. The upper diagram shows the displacements of the platform and the rigid body, respectively. In this example, where $f=15 \mathrm{~Hz}, A=2 \mathrm{~mm}$ and $a_{\text {Peak }}=1.81 \mathrm{~g}$, the rigid body will be lifted off the platform just before the platform reaches its highest position, and the rigid body hits the platform just after it reaches its lowest position. This causes a distinct impact, as demonstrated by the acceleration depicted in the lower diagram. It is obvious, however, that the human body is not completely rigid, but rather has elastic and damping properties. Nevertheless, the feet can sometimes be lifted off the platform during whole body vibration exercise, which leads to a loss of contact and skidding
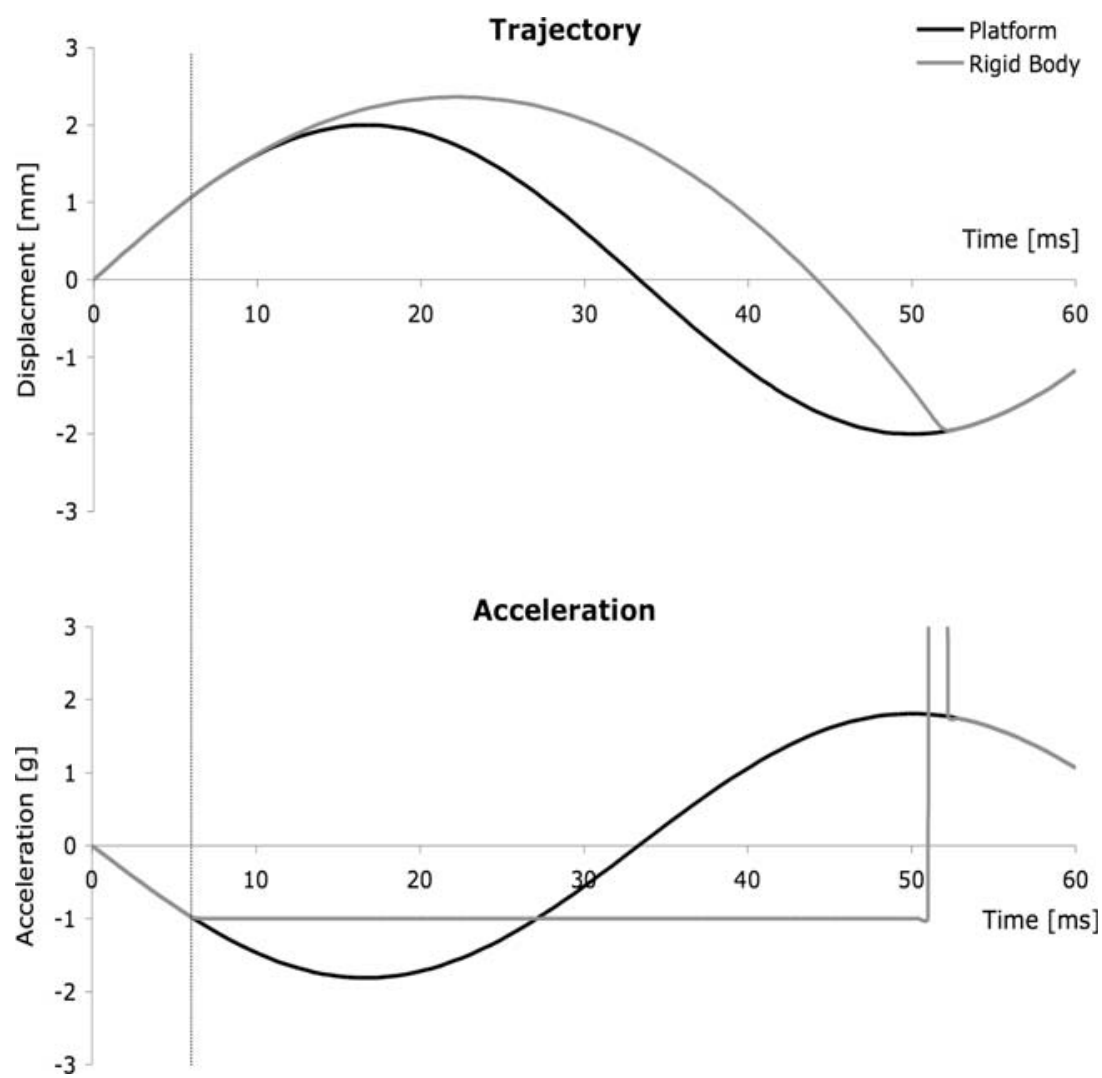

the frequency of the actuator, $\omega_{\mathrm{A}}$, matches the frequency of the resonator, $\omega_{0}$. The accumulation of energy can lead to a situation where the vibration amplitude is greater in the resonator than in the actuator. This amplitude amplification entails increased internal forces within the resonator, which can lead to its destruction-the so-called resonance catastrophe. It is crucial to bear in mind that amplitude amplification can only occur if there is little damping (see Fig. 4a). Moreover, not all amplitude amplification causes resonance catastrophe, as this will happen only if the generated forces exceed the resonator's structural strength. Nevertheless, resonance should be prevented in vibration exercise, e.g. by alteration of stiffness and thus $\omega_{0}$, or by introducing a damping element (friction). Evidence suggests that muscles have such damping properties (Wakeling et al. 2002). However, any mechanical damping will lead to the absorption of energy and thus generate heat.

Finally, considering to the human anatomy, we have to consider the way in which vibrations are transmitted. This will occur from one segment to the next, i.e. from the foot to the calf, from the calf to the thigh etc. The amount of vibration energy transmitted will depend on musculoskeletal stiffness and damping (see subsection Vibration transmission at the end of this article for specific details). Importantly, effective axial body stiffness increases with straightened limbs (Greene and McMahon 1979; Lafortune et al. 1996), which also leads to an increase in resonance frequency. Assuming an appropriate posture can therefore help to avoid resonance. Equally important, standing on the forefoot will involve the ankle joint actuators (i.e. the calf muscles) in the damping process, which is not the case when stance is on the mid-foot (see Fig. 4b). Posing weight on the forefoot, therefore, can help to avoid resonance, and also to increase damping by the musculature and thus reduce vibration transmission to the trunk. Hence, assuming an appropriate posture is the prerequisite to avoid unpleasant head and trunk vibration, and also to provide firm stance on the vibrating platform.

\section{Acute physiological effects}

Muscle and tendon mechanics

What happens to the muscle-tendon complex during vibration exercise? Given that $a_{\text {Peak }}$ levels at the head are usually much smaller than at the vibrating platform (Abercromby et al. 2007b), one has to assume that muscles and tendons will elongate at one time (stretch phase), to be followed by a period of shortening (shortening phase). In other words, vibration exercise should be characterized by cyclic transition between eccentric and concentric muscle contractions. A recent study suggests that this is indeed the case, and that the gastrocnemius muscle tendon complex is 

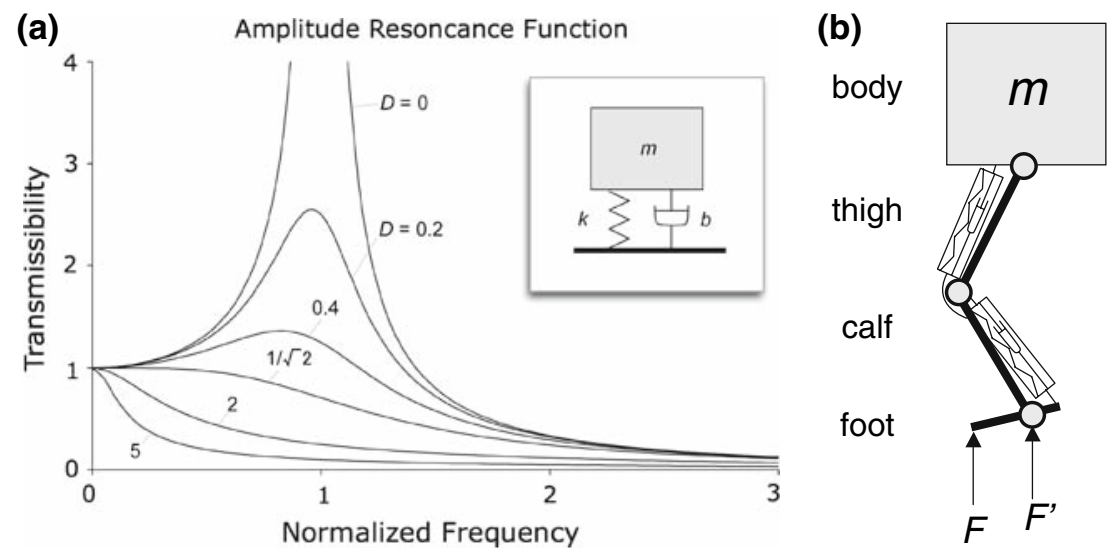

Fig. 4 Model of the human body as a resonator, composed of a single (a) or multiple (b) segments with spring-like and damping behaviour. a A mass is linked to a spring with stiffness $k$ and a dashpot with friction $b$ (see inset). This system can act as a resonator with resonance frequency $\varpi_{0}$. When driven by an actuator with angular frequency $\varpi_{A}$, transmissibility is determined by $\varpi_{A} / \varpi_{O}$ (=normalized frequency) and the grade of damping $D$. Amplitude amplification is defined by transmissibility $>1$, i.e. when the amplitude of the resonator is larger than the amplitude of the actuator. This occurs when $D$ is below a critical value and when $\varpi_{0} \approx \varpi_{A}$. Adapted from Hering et al. (2004). b The calf and thigh muscles are idealized as spring-dashpot systems, which can store and absorb energy. Force $F$ applies at the foot and thus loads the calf muscles and potentially also the thigh muscles. By contrast, force $F^{\prime}$ applies at the rotational centre

elongated by $1 \%$ of its total length during $6 \mathrm{~Hz}$ vibration cycles with $a_{\text {Peak }}=0.6 g$ (Cochrane et al. 2009).

\section{Neurophysiological responses}

Although no study has yet assessed the motor unit discharge patterns during vibration exercise, the neurophysiological responses of the muscle to isolated vibrations applied are very well studied. Applying vibration directly to the muscle belly or tendon elicits a phase-oriented discharge from primary (Brown et al. 1967; Burke et al. 1976; Homma et al. 1971; McGrath and Matthews 1973; Roll and Vedel 1982) and also secondary spindle endings (Brown et al. 1967; Burke et al. 1976; McGrath and Matthews 1973). Between the two, primary endings are more responsive than secondary endings (Bianconi and van der 1963; Brown et al. 1967). The spindle discharge depends on the pre-stretch of the muscle and generally increases with muscle length or stretch (Burke et al. 1976; Cordo et al. 1993). It is also enhanced during voluntary isometric contraction (Burke et al. 1976). In addition to the spindle afferents, Ib-afferents from Golgi tendon organs are likewise responsive to muscle vibration (Burke et al. 1976; Hayward et al. 1986). Like the spindle endings, afferents from Golgi tendon organs become more responsive to vibration when the muscle is contracting (Brown et al. 1967). The Golgi organ is believed to measure tendon of the ankle and will therefore load the thigh muscles, but not the calf muscles. Posing weight on the forefoot or on the mid-foot can thus alter the transmission of vibration and thus relative loading of calf and thigh muscles in whole body vibration exercise. Conversely, locking of the knees will reduce energy absorption in the thigh muscles and lead to greater vibration transmission to the trunk. It should be understood that this model is an over-simplification. However, it constitutes a basis for understanding the physics of whole body vibration. Several mechanical models have been developed that provide more detail than the simple sketch in this figure (Cole 1978; Ghista 1982; Yue and Mester 2002). They indicate that amplitude amplification may occur under certain circumstances, and it is therefore important to assess vibration transmission by physical measurements (see also "Vibration transmission")

elongation, and thus a surrogate of force. It elicits an inhibitory effect upon motor output via polysynaptic spinal pathways, and its information converges with that from cutaneous receptors, spindle afferents, joint receptors and others (Lundberg et al. 1975).

Importantly, spindle discharge will elicit an excitatory effect upon the $\alpha$-motoneurone, either by monosynaptic (primary or Ia afferents) or polysynaptic (secondary or II-afferents) pathways and thus foster contractions of the homonymous muscle (Granit et al. 1956). Passive muscle vibration therefore causes a reflex contraction, also known as the tonic vibration reflex (Hagbarth and Eklund 1966; Matthews 1966). It is characterized by a gradual onset, and it can be voluntarily suppressed (Hagbarth and Desmedt 1973; Lance et al. 1973). Alongside the contraction, people experience an illusion of movement during the tonic vibration reflex (Goodwin et al. 1972a, b). During the reflex contraction, the discharge from both primary and secondary spindle endings seem to decline, whereas the discharge from Golgi tendon organs is increased (Burke et al. 1976). Microneurographic evidence in humans suggests that the reflex contraction crucially depends on fusimotor efferents (Burke et al. 1976), suggesting that supra-spinal control is involved in it. In relation to this, it has been pointed out that the reflex contraction bears similarities with Kohnstamm's phenomenon (Bergenheim et al. 2000; Gilhodes et al. 1992). 
On the other hand, and in apparent contrast to the reflex contraction mediated by the Ia-loop, the stretch reflex and the H-reflex are suppressed while vibration is applied to the muscle (Arcangel et al. 1971; De Gail et al. 1966). It has been demonstrated in a decerebrated cat model that this reflex suppression is due to presynaptic inhibition, impinging upon the very spindle afferents that are activated by the vibration (Gillies et al. 1969). Apparently, this presynaptic inhibition is elicited by GABAergic interneurones (Gillies et al. 1969). In addition to presynaptic inhibition of the Ia afferents, a reduction in the sensitivity of primary spindle endings (Hayward et al. 1986; RibotCiscar et al. 1998) and transmitter depletion (Curtis and Eccles 1960) have been proposed as mechanisms to explain the reflex inhibition. Therefore, tonic contraction and phasic reflex suppression, which are both caused by the vibratory stimulation of primary spindle endings seem to be mediated by different mechanisms.

Finally, vibration applied to the patella tendon during voluntary knee extension leads to enhanced co-contraction of the hamstring muscles (Rothmuller and Cafarelli 1995), suggesting that the centrally mediated co-contraction command supersedes spinal reciprocal inhibition of the antagonist (Sherrington 1906). The apparent spinal reflex inhibition contrasts with the facilitation of cortico-spinal excitatory pathways, as demonstrated by enhancement of motor potentials evoked by transcranial magnetic stimulation during passive muscle vibration (Kossev et al. 1999), an effect that seems to be strongest with vibration frequencies around $100 \mathrm{~Hz}$, and which seems to encompass reduced excitability of the antagonistic muscles (Siggelkow et al. 1999). Interestingly, this central nervous effect seems to be active also on the contralateral side (Kossev et al. 2001).

After termination of single muscle vibration, the H-reflex continues to be reduced for some minutes (Arcangel et al. 1971; Roll et al. 1980; van Boxtel 1986). Inconsistent results have been reported for the stretch reflex, with some authors reporting enhancement (Shinohara et al. 2005; van Boxtel 1986) and others depression (Roll et al. 1980). Muscle spindles seem to be less responsive after vibration termination (Ribot-Ciscar et al. 1998).

Coming to vibration as an exercise modality, there are no studies yet on either the H-reflex or the stretch reflex during exercise. After exercise termination, a number of studies have found enhancement of stretch reflexes (Rittweger et al. 2003; Melnyk et al. 2008) and increased H-reflex responses (Nishihira et al. 2002). The postvibration reflex enhancement is in a way surprising, as one would expect a reflex depression during the vibration exercise itself, and it is probably due to facilitation of primary spindle inputs, as EMG studies suggest that only the short latency component of the reflexes is increased
(Shinohara et al. 2005). It has to be mentioned, though, that one study could not demonstrate any change in stretch reflex levels (Hopkins et al. 2008a). Unfortunately, the few studies available on this topic are quite heterogeneous with regards to the exercise parameters (time of exposure, additional loads etc.) and also to the time of assessment. Therefore, whilst literature supports the view that exposure to vibration exercise is acutely followed by reflex enhancement, the exact details and mechanisms of this enhancement are yet undetermined.

\section{EMG responses}

Recording surface EMG activity during vibration exercise is difficult, because there are several ways in which vibration-induced movement can cause EMG artefacts. These include electric induction in vibrating cables, and piezoelectric or bi-layer currents (Meyer-Waarden 1985). On other hand, there is clear evidence that passive muscle vibration is phase-linked to motor unit discharge and EMG modulations even under conditions where such artefacts can be excluded (Bongiovanni and Hagbarth 1990). Quite interestingly, the response to passive muscle vibration does not extend to muscles that are synergistic to the vibrated muscle and insert into the same tendon (Kouzaki et al. 2000).

Accordingly, a couple of studies demonstrate immediate effects of vibration upon EMG activity (Abercromby et al. 2007a; Cardinale and Lim 2003; Cochrane et al. 2009; Seidel 1988). Seated vibration with frequencies between 0.3 and $5 \mathrm{~Hz}$ ( $a_{\text {Peak }}$ levels between 1.2 and $2.0 \mathrm{~g}$ ) has been shown to elicit vibration-synchronous EMG activity in the erector spinae muscle (Seidel 1988). Probably owed to a change in the reflex pathways involved, there was a shift in phase relationship observed between 4 and $5 \mathrm{~Hz}$.

For vibration frequencies that are usually applied for exercise purposes, it seems that the effects upon vastus lateralis EMG amplitude are larger at $30 \mathrm{~Hz}$ than at 40 or $50 \mathrm{~Hz}$ (Cardinale and Lim 2003). EMG responses seem to be generally more pronounced in side-alternating as compared to synchronous whole body vibration (Abercromby et al. 2007a). In order to eliminate possible artefacts, however, a stop-band filter was applied in this study. This data treatment precludes that fraction of the EMG response that is in fixed phase relation with the vibratory stimulus, and those results therefore reflect only muscle contractions not elicited by monosynaptic reflexes.

In contrast to the above studies, which were probably involving only moderate muscle contractions, a study that applied vibration $(f=65 \mathrm{~Hz})$ to the biceps tendon during biceps curls at $70 \%$ of the one-repetition maximum could not demonstrate any effect upon the EMG (Moran et al. 2007). A possible explanation may have been anticipated 
by Hagbarth et al. $(1966,1986)$ who concluded that vibration usually increases motor activity during submaximal, but not during maximal contractions. Several mechanisms may play a role here, one being inhibition by Golgi organ afferents, due to the large force applied.

\section{Energy metabolism}

Hence, there is good evidence for an involvement of muscular contractions during vibration exercise. Moreover, applying vibration to intact or skinned single fibre preparations leads to specific increases in ATP turnover (Wang and Kerrick 2002). Accordingly, one would expect a specific energy demand arising from the exposure to vibration-which is indeed the case (Rittweger et al. 2001, 2002a). Under various conditions, such as standing, and squatting without and with an additional load, this vibration-specific $(f=26 \mathrm{~Hz}, A=3 \mathrm{~mm})$ energy turnover amounts to $4.5 \mathrm{ml} \mathrm{min} \mathrm{mg}^{-1}$ (Rittweger et al. 2001). It can be further enhanced by increasing frequency and amplitude of vibration, as well as by additional loads (Rittweger et al. 2002a). More specifically and based on the linear relationship between vibration frequency and oxygen uptake, there seems to be an oxygen demand of $2.5 \mu \mathrm{kg}^{-1}$ per vibration cycle for an amplitude of $5 \mathrm{~mm}$. The influence of vibration amplitude, by contrast, seems to be essentially non-linear and more pronounced with increasing amplitude. Muscular ATP turnover during vibration $(f=20 \mathrm{~Hz}$, $A=2 \mathrm{~mm}$, one-legged) has recently been studied by ${ }^{31} \mathrm{P}$ magnetic resonance spectroscopy (Zange et al. 2008a). Interestingly, this vibration-related ATP consumption led to a decrease in intracellular PCr levels only when arterial occlusion impeded oxidative phosphorylation and thus ATP re-generation (Zange et al. 2008a), underlining the importance of muscle perfusion in vibration exercise.

Can this kind of energy turnover help to reduce body weight? To make an example, a typical $70 \mathrm{~kg}$ person, while performing a standard vibration regimen would consume $\approx 201$ of oxygen per hour. Assuming an energy equivalent of $20.9 \mathrm{~kJ}$ per litre oxygen and a caloric equivalent of $39 \mathrm{~kJ}$ for each gram of body fat (Cook et al. 2000), this would imply a loss of only $\approx 10 \mathrm{~g}$ of fat for each hour spent in that kind of exercise. It seems clear from these figures that vibration exercise is not a viable option to directly lose body fat. Likewise, vibration by itself will probably not affect aerobic fitness, given that energy turnover and cardiorespiratory responses are only moderate (McCloskey et al. 1972; Rittweger et al. 2000, 2001, 2002a).

\section{Intramuscular temperature}

One would expect that the vibration-related increase in muscular energy metabolism leads to the generation of additional heat. Indeed, intramuscular temperature increases during whole body vibration exercise have recently been reported (Cochrane et al. 2008b). However, these increases were faster in whole body vibration than in stationary bicycling, even though both modalities were matched for oxygen uptake, and thus supposedly for muscular energy metabolism. It is tempting to explain the vibrationrelated warm-up effect at least partly by shock-absorbing mechanisms within the muscle (Wakeling et al. 2002), and thus transformation of mechanical energy into heat.

\section{Skin and muscle perfusion}

Hence, given that vibration exercise stipulates muscular energy turnover and heat production, there is an obvious need for perfusion to comply with increased demands. However, acute hand-transmitted vibration has been shown to reduce digital blood flow (Welsh 1980), probably through sympathetic nervous activity (Egan et al. 1996), and vibration has therefore been thought to inhibit perfusion. This view has recently been challenged (Nakamura et al. 1996), when hand-transmitted vibration $(f=120 \mathrm{~Hz}$, $a_{\text {RMS }}=5 \mathrm{~g}$ ) was shown to increase rather than to decrease digital blood, probably through mediation by reduced secretion of endothelin-1 from vascular smooth muscle cells. It therefore seems that hand-held vibration can employ different mechanisms and thus cause diverging effects upon perfusion.

During whole body vibration exercise there is an enhancement of skin blood flow, as measured by laserDoppler flowmetry (Lohman et al. 2007; Maloney-Hinds et al. 2008; Rittweger et al. 2000). Similar findings have been made in passive vibration (Oliveri et al. 1989) where the effect seems to be most pronounced at vibration frequencies around $30 \mathrm{~Hz}$ and lower (Homma and Desmedt 1973). Moreover, a stocking-like itching erythema has been described that occurs mainly in women during the first training units of whole body vibration (Rittweger et al. 2000). It seems likely that vibration-induced shear forces in the skin cause vasodilation, similar to dermographism (Lewis 1924; Wong et al. 1984), which is thought to be mediated by histamine deliberation from mast cells (Greaves and Sondergaard 1970). Although not reported so far, one should therefore be prepared to see vibratory angioedema in response to vibration exercise in some rare instances (Lawlor et al. 1989). This disorder is either genetically transmitted (very rare) or acquired. It can be accompanied by chest tightness and dizziness, but is not thought to be threatening (Lawlor 2000).

With regards to muscle perfusion, a $100 \%$ increase in popliteal blood flow, along with an increase in gastrocnemius and vastus lateralis muscle blood flow have been found after termination of vibration exercise $(f=26 \mathrm{~Hz}$, 
$A=3 \mathrm{~mm}$, side-alternating) (Kerschan-Schindl et al. 2001). Similarly, reduced pulse wave velocity and thus reduced arterial stiffness have been reported (Otsuki et al. 2008), likewise suggestive of arterial vasodilation in the vibrated musculature. However, as the above studies have focussed on post vibration exercise measurements, one could also suspect reactive hyperaemia as a cause (Doshi et al. 2001), and thus hypoxia during the exercise.

This view is partly supported by studies that assessed tissue oxygenation with near-infrared spectroscopy (NIRS). During whole body vibration exercise $(f=15 \mathrm{~Hz}$, $A=2.5 \mathrm{~mm}$, side-alternating), combined with squatting exercise, an increase in tissue oxygenation was found when the leg muscles were vibrated passively (Yamada et al. 2005). However, there was a decrease in tissue oxygenation during squatting exercise that was further aggravated in the presence of whole body vibration (Yamada et al. 2005). Accordingly, it was concluded from that study that vibration exercise induces muscle deoxygenation, and that this might constitute an effective training stimulus. Other studies have challenged this view and suggested that vibration affects muscle perfusion only at certain frequencies (Calvisi et al. 2006; Cardinale et al. 2007). Moreover, there are also time- and frequency dependant increases of muscle perfusion during vibration exercise, in particular during the first minute (Cardinale et al. 2007; Rittweger et al. 2009b).

Taken together, it therefore seems that vibration can affect muscle perfusion, perhaps depending on metabolic rate, intramuscular pressure and other factors. It seems also that muscular perfusion, under unimpeded conditions, attempts to match up for the metabolic demands of the contracting musculature during vibration exercise (Zange et al. 2008a). Hence, the increase in vascular endothelial growth factor (VEGF) during exercise close to peak metabolic rate on a vibrating bicycle as observed by Suhr et al. (2007) could or could not be due to tissue hypoxia. Importantly, deliberation of VEGF is not only caused by hypoxia (Forsythe et al. 1996), but also by endothelial shear stress (Milkiewicz et al. 2001). However, whole body vibration exercise at low metabolic rate does not lead to any change in serum VEGF levels (Rittweger et al. 2009b), which either means that there is no VEGF deliberated in the muscle in response to vibration, or that any such release is too small to affect serum levels.

Acute effects of vibration on muscle force, power and fatigue

\section{Single muscle vibration}

Earlier studies with an occupational background have reported accelerated muscle fatigue by vibration (Farkkila et al. 1980; Samuelson et al. 1989). This is in some contrast to a number of physiological studies that report tendon vibration to increase motor output and force production when added onto a moderate isometric contraction (Bongiovanni and Hagbarth 1990; McCloskey et al. 1974). Moreover, brief bouts of vibration can reinstate EMG amplitude, and to a lesser degree force generation applied in a muscle fatigued by isometric contraction (Bongiovanni and Hagbarth 1990; Gabriel et al. 2002). This enhancement, however, lasts only $10 \mathrm{~s}$ and reverts to its contrary after this time and to accelerated fatigue progression (Bongiovanni and Hagbarth 1990). It is unlikely that this additional fatiguing effect by vibration is caused by metabolic or circulatory mechanisms within the muscle, because the same decline in force generation is observed when producing short, intermittent maximal contractions and continuously applying vibration. Apparently, it is limited to the very muscle that is vibrated and does not extend to synergists inserting into the same tendon (Kouzaki et al. 2000). Therefore, the vibration-related inhibitory effect seems to be well explicable by the presynaptic inhibitory mechanism that has been discussed above (see "Neurophysiological responses"), and it may be caused by high thresholds motor units only (Bongiovanni and Hagbarth 1990; Bongiovanni et al. 1990), which may be identical with the large motor units according to Henneman's principle (Henneman 1985), and which consequently must be expected to be more fatigable.

Although it is difficult to summarize these observations, it seems reasonable to assume that fusimotor-driven Ia discharge is crucial to maximal voluntary contractions, that the Ia discharge somehow saturates at maximal force levels, and that vibration can sometimes bypass the central fusimotor drive and thus boost the Ia discharge (Bongiovanni and Hagbarth 1990). What is remarkable in the context of vibration as an exercise modality, however, is that vibration will have no or a even small negative effect on maximal voluntary contraction force in the non-fatigued state, but that it can alleviate muscle fatigue for a short time, only to finally aggravate the fatigue. Finally, it should be remembered that some motor units are turned on by vibration more easily than others (Bongiovanni and Hagbarth 1990; Bongiovanni et al. 1990). Importantly, it is the high threshold units with depict rapid fatigue, both during voluntary contractions as well as during vibration, and which contribute largely to the inhibitory effects of vibration.

\section{Vibration as an exercise modality}

Bosco et al. (1999b) were the first to study the acute effects of vibration as an exercise modality on muscular power. After ten 60 -s bouts of whole body vibration $(f=26 \mathrm{~Hz}$, 
$A=5 \mathrm{~mm}$, one-legged), the authors found an increase in leg press power by $6-8 \%$ in young elite volleyball players. Very similar effects have been reported for elbow flexion in power elite boxers (Bosco et al. 1999a) and a mixed group of elite athletes (Issurin and Tenenbaum 1999), for jump height in elite hockey players (Cochrane and Stannard 2005) and for the one-repetition maximum in recreationally active people (Mileva et al. 2006). One study demonstrated an acute effect of vibration exercise on jump height in women, with increasing effect size when increasing the frequency of vibration over the same period of time (Bazett-Jones et al. 2008), but no effect was found in men. On other hand, isometric force generation seems to be acutely depressed by $\approx 5 \%$ after vibration exercise, as reported by a number of studies (De Ruiter et al. 2003b; Erskine et al. 2007; Herda et al. 2008).

Taken together, the literature therefore is quite unanimous in stating that muscular power output can be acutely increased by vibration exercise whilst force generation capacity seems to be depressed post vibration exercise. It is often argued that the enhancement of muscle power during and immediately after vibration is linked to neuromuscular facilitation (Cochrane et al. 2004; Delecluse et al. 2003; Issurin and Tenenbaum 1999). However, this notion is not compatible with the neurophysiological responses outlined above, and it is contradicted by the apparent depression of force generation (De Ruiter et al. 2003b; Erskine et al. 2007; Herda et al. 2008), which is suggestive of persisting inhibition rather than facilitation. It seems to make more sense, therefore, to ascribe the observed power enhancement to the well-documented warming-up effect (Cochrane et al. 2008b), as it is well known that muscle temperature has a strong effect upon muscular power, but only a very small effect upon force generation (De Ruiter and De Haan 2000). In fact, the study by Cochrane et al. (2008b) reports comparable power increases across different warm-up modalities (passive, bicycling, vibration and dynamic squat) when intra-muscular temperature increases were likewise comparable, underlining the central role to muscle temperature for power generation. If this view holds true, then vibration exercise could be a favourable means of warming-up in sports where muscle power is crucial, provided that any inhibitory effects upon muscle power by vibration exercise are smaller than the positive temperature effects.

\section{Cutaneous receptors and pain perception}

Finally, the well-known effects of vibration upon the mechano-receptors in the skin also need to be discussed here. Of these, there are two kinds that are specialized in the transduction of vibratory stimuli: Meissner corpuscles are most responsive around $40 \mathrm{~Hz}$, and the Vater-Pacini corpuscles at $100 \mathrm{~Hz}$ and above. Together, they are also referred to as fast adapting cutaneous receptors. By contrast, the Merkel cells and Ruffini endings are referred to as slowly adapting, and are classically described as sensitive to sustained pressure (Martin and Jessell 1991). Quite surprisingly, however, a recent study by Ribot-Ciscar et al. suggest that both fast as well as slowly adapting receptors are sensitive to vibration, the difference being that fast adapting receptors become quiescent above a certain stimulation frequency (Ribot-Ciscar et al. 1989). Importantly, the processing of pressure and touch is masked during vibration (Ribot-Ciscar et al. 1989), and also after the vibration is set off (Ribot-Ciscar et al. 1996). However, some cutaneous mechanoreceptor afferents seem to be aroused for many minutes post vibration (Ribot-Ciscar et al. 1996), which may be the physiological basis of the tingling sensation often experienced after exposure to vibration. Practically, this means that the sense of touch is acutely disturbed during and shortly after vibration exercise.

Given that vibration strongly affects the afferent discharge from fast adapting mechanoreceptors and muscle spindles, one might speculate that, according to the gate control hypothesis (Melzack and Wall 1965), vibratory stimulation could be utilized in a fashion similar to transcutaneous electrical nerve stimulation (TENS) (Guieu et al. 1991) in order to reduce the perception of pain. Indeed, literature does provide evidence for this idea, as applying passive vibration has led to pain reduction in $70 \%$ of patients with acute and chronic musculoskeletal pain (Lundeberg 1984; Lundeberg et al. 1984). Similarly, passive $80 \mathrm{~Hz}$ vibration has been shown to reduce pain caused by muscle pressure (Weerakkody et al. 2001). However, the pain-reducing effect by vibration in that study was perverted into its contrary in the presence of delayed onset muscle soreness (DOMS). More recent evidence suggests that pain perception in DOMS depends partly on fast myelinated afferent fibres, i.e. fibres that are distinct from those that convey most other types of pain (Weerakkody et al. 2003).

\section{Posture and stance}

As mentioned above, application of vibration to single muscles causes a movement illusion (Goodwin et al. 1972b) towards the opposite direction as the reflex contraction. Interestingly, this reflex contraction interferes with proprioception and leads to positioning errors even after the cessation of vibration (Rogers et al. 1985). It therefore seems logical that tendon vibration also has immediate (Eklund 1969, 1972, 1973; Lackner 1988) and protracted effects (Wierzbicka et al. 1998) upon stance and posture. More specifically, vibration of the tibialis anterior tendon elicits sway towards the rear, whereas Achilles tendon 
vibration elicits sway towards the front (Wierzbicka et al. 1998). These effects have to be understood as general reactions of the central nervous system, rather than local effects on single muscles, as body sway typically involves many muscles and can be induced from many muscles within the body, including neck and extraocular eye muscles (Ivanenko et al. 1999). The effect can be quite strong, and vibration of the Achilles tendon can cause falling backwards (Eklund 1972). Again, this cannot be understood as a mere effect of peripheral disturbance, but is rather disclosing the relative attention of the central nervous system to different afferent streams. This view is illustrated by the fact that reduction of support stability seems to reduce, rather than to increase, the tendency of vibration induced falling (Ivanenko et al. 1999), and that this occurs in a direction-specific way (Ivanenko et al. 2000).

It is also important here to consider that afferents from cutaneous mechanoreceptors can affect motor reflexes and stance (Magnusson et al. 1990). The specific effects often depend on the exact anatomical location of the cutaneous receptor, but also on the specific motor pattern. This is in particular true for the foot sole where application of pressure elicits reflex contractions of specific leg muscles, depending on the precise point of application (Layne et al. 2005). Timing of the stimulus, body configuration and postural instability are likewise important factors that modulate these sole impression reflexes (Forth and Layne 2008; Layne et al. 2002). One can therefore think of the foot-sole as a complex interface to modulate posture and gait.

In this sense, pressure as well as vibration have been shown to affect posture in close relation to the anatomical location of application, and both modalities have mutually opposing effects upon posture (Kavounoudias et al. 1998). Vibratory foot stimulation causes a shift of posture towards the front when applied under the heel, and to the rear when applied under the forefoot (Kavounoudias et al. 1999). The latter effect increases linearly with the frequency of vibration, and vibratory effects from the forefoot and from the heel seem to antagonize each other (Kavounoudias et al. 1999). In a somewhat similar way, vibratory stimulation of the tibialis anterior and gastrocnemius muscles seem to have antagonistic effects upon posture (Polonyova and Hlavacka 2001). Moreover, unilateral application of muscle vibration can cause sway in the frontal plane (Polonyova and Hlavacka 2001). Finally, comparing vibratory foot-sole and tendon stimulation, there seem to be an integrated postural response (Kavounoudias et al. 2001), the outcome of which is determined by site of application and vibration frequency.

Hence, vibration application to the foot-sole, as well as other tactile information, has profound and immediate effects upon posture and balance. On other hand, stance on vibrating platforms is generally firm even in frail elderly (Runge et al. 2000), and there have been, to the best of my knowledge, no reports of falls. It therefore seems that people do have control of their posture during vibration exercise, probably accounting for the vibratory effects.

Joint stability

One could speculate that the alteration of reflex levels by vibration, as discussed above, might help to improve joint stability. A recent study confirms this view (Melnyk et al. 2008) and reports enhanced short latency responses to anterior cruciate ligament stretch (see "Neurophysiological responses"). This may be due to enhanced efficacy of the monosynaptic pathway, resulting in improved knee stability and reduced anterior tibial displacement upon shock provocation, and implying potential protection from anterior cruciate ligament injury.

By contrast, a study on ankle stability could not find any effect by acute vibration (Hopkins et al. 2008b). More studies are required, therefore, before a judgement can be made as to any joint protective effects by vibration exercise.

\section{Flexibility}

Static and dynamic stretching are standard methods to improve flexibility before engaging in exercise activities (Dadebo et al. 2004). It is thought that mechanical stretching can reduce the stiffness of tendon (Kubo et al. 2001), intramuscular connective tissue (Morse et al. 2008), and possibly other passive skeletal structures that together define the range of motion for a given joint (Magnusson et al. 1997). Provided that vibration exercise involves mechanical stretching (see "Muscle and tendon mechanics"), there is good justification for the idea to increase flexibility by vibration exercise (Atha and Wheatley 1976).

In support of that idea, an $8.2 \%$ improvement in the sit and reach has been reported after acute whole body vibration exercise (Cochrane and Stannard 2005). Similarly, vibration-assisted stretching for $4 \times 10 \mathrm{~s} \quad(f=30 \mathrm{~Hz}$, $A=2 \mathrm{~mm}$ ) enhanced the forward split in competitive female gymnasts (Kinser et al. 2008), suggesting improved flexibility in these elite athletes. By contrast, other studies could not find any acute vibration-specific effect upon musculo-tendinous stiffness in the triceps surae muscle (Herda et al. 2008) or the hamstring muscles (Cronin et al. 2008).

\section{Hormonal responses}

Exercise evokes endocrine responses that can be understood as regulatory signals required to accomplish the exercise 
task, but also as mediators for the training effect (Viru 1992). As such, hormone responses to exercise have been documented for testosterone (Kindermann et al. 1982; Kraemer et al. 1990), the growth hormone/IGF axis (Kindermann et al. 1982; Kraemer et al. 1990), catecholamines (Kindermann et al. 1982; Kjaer 1998) and others. Hormonal responses to vibration exercise can therefore inform us about the specific physiological processes engendered by it.

\section{Testosterone}

The initial report of small but significant increases of testosterone levels in response to whole body vibration exercise (Bosco et al. 2000) could not be confirmed by subsequent studies (Cardinale et al. 2006; Di Loreto et al. 2004; Erskine et al. 2007). Moreover, Kvorning et al. (2006) demonstrated increase in plasma testosterone levels in response to conventional resistive exercise with or without vibration, but not in response to vibration alone, suggesting that there is probably no vibration-specific effect upon testosterone deliberation.

\section{Growth hormone $(G H)$ and IGF-1}

An originally reported acute increase of GH levels after vibration exercise (Bosco et al. 2000) could not be replicated by subsequent studies (Cardinale et al. 2006; Di Loreto et al. 2004; Goto and Takamatsu 2005). However, one should consider that $\mathrm{GH}$ is released in a pulsatile fashion (Corpas et al. 1993), and that it is therefore inherently difficult to monitor its acute responses to exercise. Quite interestingly, another study found vibrationspecific GH responses that were potentiated when combining vibration with conventional resistive exercise (Kvorning et al. 2006). Moreover, whole body vibration fosters IGF-1 levels in elderly people (Cardinale et al. 2008), thus suggesting that there may indeed be a vibration-specific effect on the GH-IGF axis.

\section{Cortisol}

Whilst exercise often leads to increased serum cortisol levels, there is some evidence to suggest that vibration may have the contrary effect (Bosco et al. 2000; Kvorning et al. 2006). However, other studies contradict this notion and even report an increase in cortisol levels in response to whole body vibration (Erskine et al. 2007; Cardinale et al. 2008).

\section{Catecholamines}

Literature states unanimously that catecholamine levels in the blood are acutely increased after vibration exercise (Di
Loreto et al. 2004; Goto and Takamatsu 2005). This neuroendocrine response has been proposed to be the reason for reduced gastric motility during whole body vibration (Ishitake et al. 1999), although direct mechanical influences could also play a role.

\section{Blood lipids}

An increase in serum free fatty acids, but not in glycerol, has been reported $150 \mathrm{~min}$ after the vibration exercise (Goto and Takamatsu 2005). As proposed by the authors, mainly because of the considerable time lag, this is more likely to be related to the non-significant increase in GH observed in that study than to catecholamine action.

\section{Blood glucose}

Evidence suggests that vibration exercise may lead to reduced blood glucose levels (Di Loreto et al. 2004). Given that insulin and glucagon levels were not affected in that study the most likely explanation would be an enhanced glucose uptake from the blood, probably into the musculature.

\section{Adaptive and training effects}

Neuromuscular adaptation

The literature available on the effects of vibration training programs upon the musculature has been summarized in Table 1. Although there were different protocols applied in those studies, the table discloses some common features. Firstly, vibration frequency ranged between 20 and $45 \mathrm{~Hz}$ in all studies. Secondly, training programs were mostly constructed with a few bouts lasting between 1 and $2 \mathrm{~min}$. Thirdly, most programs involve three or more training sessions per week, as would be the standard for resistive training. Moreover, most studies encouraged participants to change between different exercises and postures, e.g. between different types of squats and lunges. As a general rule, smaller vibration amplitudes have been applied with synchronous than with side-alternating vibration. This is probably owed to greater vibration transmissibility towards trunk and head for synchronous vibration (Abercromby et al. 2007b).

\section{Effects by vibration training}

Looking at the outcome in Table 1 it seems that jump height is consistently enhanced by vibration training in elderly people (Bogaerts et al. 2007a; Roelants et al. 2004b; Russo and Lauretani 2004; Russo et al. 2003). 


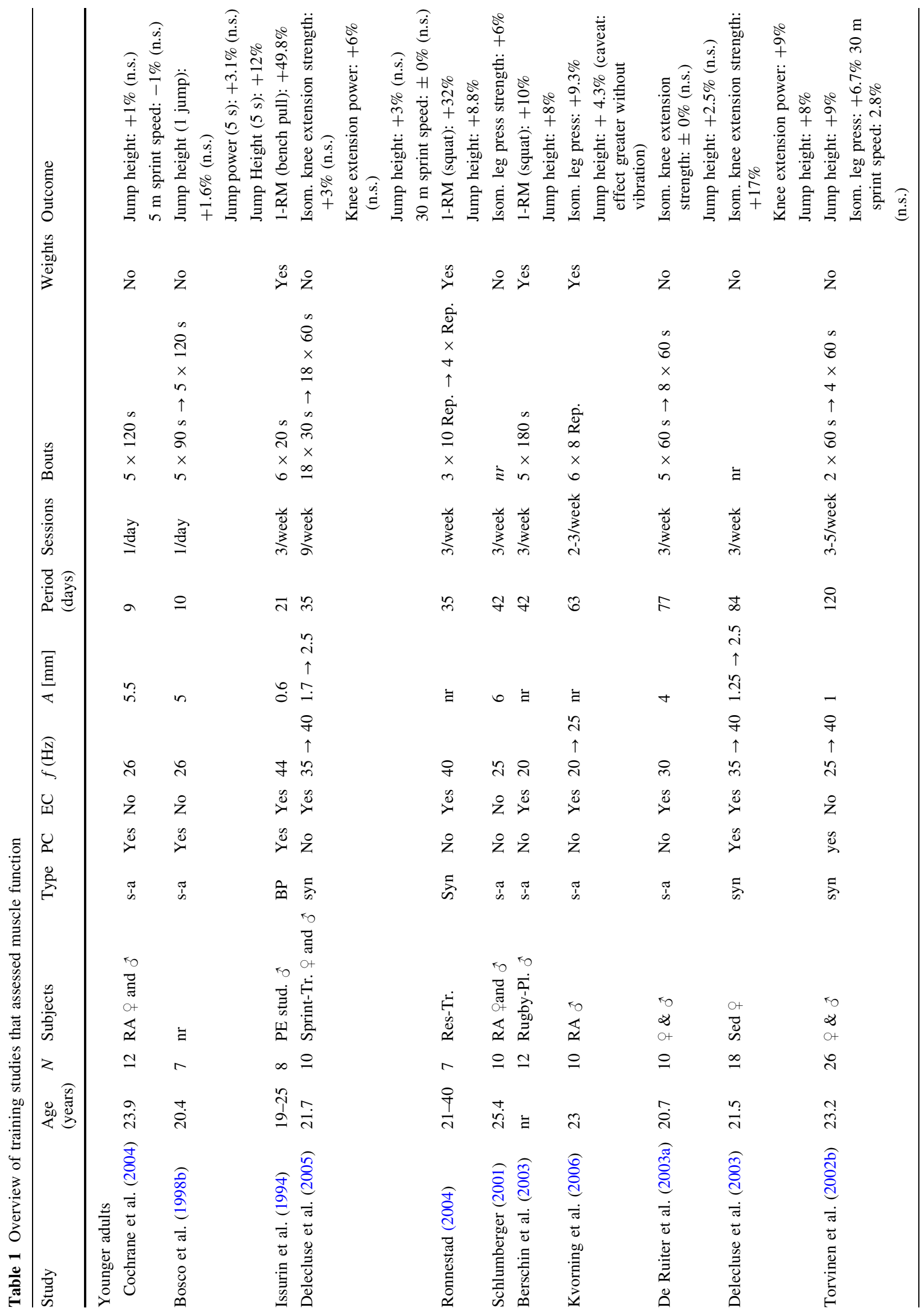




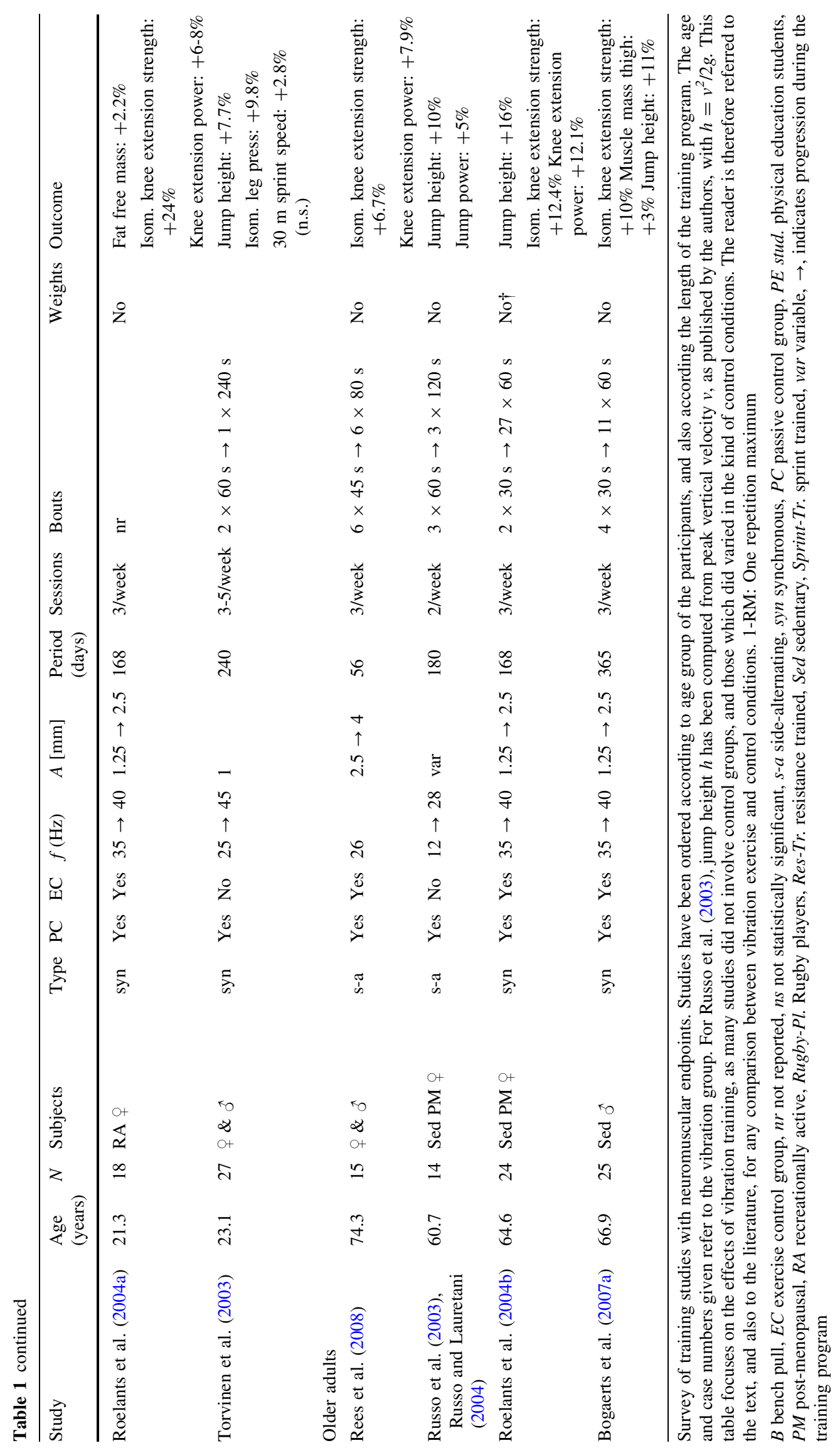


Likewise, in many studies younger people report improved jump height (Berschin et al. 2003; Bosco et al. 1998b; Delecluse et al. 2003; Ronnestad 2004; Torvinen et al. 2002b; Torvinen et al. 2003), although some other studies could not find a significant effect (Cochrane et al. 2004; De Ruiter et al. 2003a; Delecluse et al. 2005; Kvorning et al. 2006). However, these latter studies were based on small sample sizes (10-12 particpants only), which may have prevented the positive changes observed in these studies from becoming statistically significant. Moreover, the nonsignificant change $(+3 \%)$ observed by Delecluse et al. (2005) was in people who were already sprint-trained, which may reflect the general difficulty of improving performance in well-trained athletes. It therefore seems that literature favours the view of an increase in jump height as a result of vibration training (Rehn et al. 2007), and that it does so with shorter time requirements than conventional resistance training (Verschueren et al. 2004).

Such increase in jump height seems to be accompanied by a comparable increase in knee extension power (Bogaerts et al. 2007a; Delecluse et al. 2003; Roelants et al. 2004a) and also in jumping power (Russo et al. 2003). Changes in isometric muscle strength were less consistent, with one study reporting no change at all (De Ruiter et al. 2003a) and another reporting a 24\% increase (Roelants et al. 2004a). Where it was assessed, the increase in muscle power was paralleled by an increase in muscle mass (Bogaerts et al. 2007a; Roelants et al. 2004a). On other hand, the purported improvement in muscle power does not seem to translate very well into sprinting capability (Cochrane et al. 2004; Delecluse et al. 2005). This may reflect that sprint running is a more complex task than mere knee extension or vertical jumping, and that other factors involved, such as reaction time, motor patterns and tendon force transmission are not improved by vibration training in the same way as is apparently the case for muscle power.

It is also informative to study Table 1 in relation to the time factor. Substantial and significant gains in muscle power were more or less consistently achieved with training intervals of at least 6 weeks, after which there may not be any further improvement. In line with this view, all of the improvement was achieved after 12 weeks in the 24-week study by Roelants et al. (2004b), and no substantial change in muscle power was observed in Torvinen's study between 4 months (Torvinen et al. 2002b) and 8 months (Torvinen et al. 2003).

No study has yet examined the effects of vibration exercise upon skeletal muscle structural characteristics in humans, but a study in young rats suggests induction of hypertrophy in type 1 fibres and both hypertrophy and hyperplasia of type 2 muscle fibres by low magnitude vibration (see section on bone for the rationale behind the so-called low-magnitude vibration) (Xie et al. 2008).
Moreover, there seems to be a reduced number of capillary and small vessels whithin the soleus muscle, in particular in its end region (Murfee et al. 2005). This would indicate a deterioration in blood perfusion, which is in contrast to some hopes and speculations discussed earlier (Suhr et al. 2007).

\section{Comparing vibration training and conventional resistance training}

Relatively few studies have explored how vibration compares with conventional resistive training. Some studies suggest that both modalities would enhance isometric strength and isokinetic power to very similar degrees (Bogaerts et al. 2007a; Delecluse et al. 2003; Roelants et al. 2004a). However, one study found an additional enhancement of isodynamic knee extension power by vibration exercise (Roelants et al. 2004b), and another study reports improvement in jump height by vibration, but not by conventional resistance training in untrained young women (Delecluse et al. 2003).

It is a related question to ask what the effects of vibration exercise might be when added on top of conventional resistive exercise. Two studies report greater improvement of muscle power by the combination of vibration and resistive exercise (Berschin et al. 2003; Issurin et al. 1994), and a third one reports an enhancement that was on the border of statistical significance (Ronnestad 2004). In the same context, Delecluse et al. (2003) report an improvement, albeit non-significant $(p=0.07)$ in jump height and muscle power after 5-weeks of additional vibration training in sprint trained athletes. It is of interest that these studies have been performed in people who were already highly trained (see above). Conversely, the opposite was found in a study in recreationally active people (Kvorning et al. 2006), namely that resistive squatting exercise elicited slightly greater benefits in isometric leg press force and vertical jump performance when performed without rather than with vibration.

\section{Effects upon bone}

Two different philosophies have been employed to justify the application of vibration for enhancement of bone strength (Cardinale and Rittweger 2006). The first school of thought holds muscle contractions to cause the greatest forces that load our bones (Rittweger 2007), and that accordingly our bones will be adapted to these forces (Schiessl et al. 1998; Schonau et al. 2002). Therefore, vibration is thought of as an instrument to enhance bone strength through these musculoskeletal forces.

Indeed, literature does indicate specific bone-strengthening effects by whole body vibration exercise in post- 
menopausal (Verschueren et al. 2004) and older women (Gusi et al. 2006). No benefit by vibration was observed in a study of young women (average age 27 years) (Torvinen et al. 2003), suggesting that osteogenic effects may be larger in old than in young women. On other hand, vibration exercise had no additional benefit in older osteoporotic women who started anti-osteoporosic treatment with alendronate (Iwamoto et al. 2005), which may mean that whole body vibration exercise is less powerful than bisphosphonate treatment, or that it is not effective in osteoporotic women.

A second school of thought argues that, in addition to strain magnitude, signals such as strain rate (Mosley and Lanyon 1998; O'Connor et al. 1982), strain energy density, or fluid flow (Klein-Nulend et al. 1995; Turner et al. 1994) may serve as osteogenic stimuli. It is furthermore argued that many low-magnitude vibratory stimuli may have the same effect as a few high-magnitude ones (Rubin et al. 2001c). This offers the possibility to utilize low-magnitude vibratory stimuli to strengthen the bones of osteoporotic patients without the very risk of fracturing them.

Early studies in sheep yielded a $34 \%$ increase in trabecular bone mineral density in the femur following hind limb vibration ( $f=30 \mathrm{~Hz}, a_{\text {Peak }}=0.3 g$, synchronous) for 20 min per day (Rubin et al. 2001a, 2002), and a study in rat $\left(f=90 \mathrm{~Hz}, a_{\text {Peak }}=0.25 \mathrm{~g}\right)$ found an almost twofold increase in bone formation rate (Rubin et al. 2001b). Interestingly, this vibration regime could also normalize bone formation rate in hind-limb suspension (Rubin et al. 2001b) and after ovariectomy (Judex et al. 2007). However, the latter effect seemed to be specific to the $90 \mathrm{~Hz}$ vibration and was not elicited at $45 \mathrm{~Hz}$. Similarly, $45 \mathrm{~Hz}$ vibration $\left(a_{\text {Peak }}=0.3 g, 15 \mathrm{~min} /\right.$ day for 3 weeks $)$ had no effect on bone formation rate in skeletally immature mice, but it reduced the surface covered by osteoclasts in the secondary spongiosa under the growth plate (Xie et al. 2006). It is, of course, tempting to equate reduced osteoclastic surface with osteoclastic activity. A follow-up study by the same authors, however, puts this into perspective, as the same vibration regime over a longer period (6 weeks) had no effect upon osteoclastic and trabecular bone formation rate (Xie et al. 2008). There was, however, an increase in total bone volume (and thus size), with no difference in the density of the trabecular network (Xie et al. 2008), suggesting that the effectiveness of vibratory stimuli may level off, and that their long-term application in these growing mice affected bone size more than the structural make-up of the limb bones.

Another straightforward set of studies elucidated the effectiveness of movement per se. One such study has tested mere acceleratory movements causing strains along the main tibia axis as small as $1-2 \mu$ strain (i.e. a change in length in the order of $10^{-6}$ ) (Garman et al. 2007b). Despite the small magnitude, increases in trabecular bone formation rate and in epiphyseal cortical thickness were observed (Garman et al. 2007b). The same acceleratory stimulus was also found to mitigate the reduction in bone formation rate induced by immobilization (Garman et al. 2007a). However, that attenuation was only moderate, with the protective effect ranging between 26 and 44\% (Garman et al. 2007a), which seems to demonstrate that the acceleratory signals have some limited osteogenic effects on their own, and that bone strains may be required for the full efficacy of vibratory stimuli.

With regards to humans, low-magnitude vibration $\left(f=30 \mathrm{~Hz}, a_{\text {Peak }}=0.2 g\right)$ seems to counteract bone losses from the spine and perhaps also from the hip in women after menopause (Rubin et al. 2004). Moreover, it has been demonstrated to enhance the accrual of bone mass in young women with low areal bone mineral density (Gilsanz et al. 2006). Moreover, an increase was observed in paraspinous and quadriceps muscle cross section in the vibration group, but no muscle function data are available in this study. However, if the effects of this $0.2 g$ vibration upon the musculature can be substantiated, then this would constitute a remarkable finding that hints at possible alternative pathways involved in muscle hypertrophy, independent on large forces or energy turned over (Rennie et al. 2004).

Finally, low-magnitude vibration $\left(f=90 \mathrm{~Hz}, a_{\text {Peak }}=\right.$ $0.3 g$ ) has been reported to enhance bone strength in children with low bone mineral density due to disabling conditions (cerebral palsy). After standing on the active device for $10 \mathrm{~min} /$ day over 6 months, the intervention group had an increase by $6 \%$ in their proximal tibia's trabecular bone mineral density, whereas the control group (which admittedly was older) had lost $12 \%$ (Ward et al. 2004). No effect was found at the tibia diaphyisis, in the spine or in calf muscle size. Nevertheless, these results are encouraging, even though the observed increase was moderate in absolute terms.

\section{Flexibility}

As discussed above, some evidence suggests improvement of flexibility by acute vibration exercise. As to training effects, there is to date only one study (van den Tillaar 2006), which found that whole body vibration in combination with squatting exercise $(f=30 \mathrm{~Hz}, A=5 \mathrm{~mm})$ before and in between bouts of conventional stretching increased the range of movement by another $30 \%$.

\section{Postural control}

Vibration training does not seem to have any effect upon postural sway during unchallenged stance in young (Torvinen et al. 2003) or in old people (Verschueren et al. 
2004). However, postural sway during perturbed stance was reduced in response to vibration training in the latter study (Verschueren et al. 2004). Moreover, coping with complex postural challenges improved following an 8 months intervention in elderly women (Gusi et al. 2006), suggesting improvement of challenged balance in elderly people by whole body vibration training.

\section{Vibration as a countermeasure for muscle and bone during space flight}

Another potential field of application for vibration exercise is space flight, where microgravity-induced immobilisation of the lower extremity, potentially in combination with confinement and stress, lead to musculoskeletal de-conditioning (LeBlanc et al. 2007; Pavy-Le Traon et al. 2007). Hind limb suspension in rat, and bed rest in humans are broadly accepted ground-based models to study those deconditioning effects on Earth. Recent years have seen the attempts to develop countermeasures to safeguard longterm space missions, for example to Mars. For preservation of bone, bisphosphonates, i.e. osteoclast inhibitors, have proven potentially beneficial (LeBlanc et al. 2002; Watanabe et al. 2004), but there is currently no drug to counteract muscle wasting. First results suggest resistive exercise as a modality to prevent muscle atrophy and bone loss from the lower extremity (LeBlanc et al. 2000; Rittweger et al. 2005; Shackelford et al. 2004).

\section{Animal studies}

A study in rat has examined Achilles tendon vibration ( $f=120 \mathrm{~Hz}, A=1.5 \mathrm{~mm}$ for $192 \mathrm{~s}$ per day) as a potential countermeasure in hind limb-suspended rats (Falempin and In-Albon 1999). Losses in muscle mass and isometric force could be halved by the vibration treatment, with the countermeasure effect being larger for Type- 2 fibres than for Type-1 fibres.

\section{Bed rest studies}

Quite disappointing results are reported by a recent study that explored the potential of whole body vibration to prevent muscle atrophy during 2 weeks of bed rest (Zange et al. 2008b). That study was designed to examine the effects of vibration per se, and vibration was thus performed twice daily in an upright position $(f=20 \mathrm{~Hz}$, $A=2-4 \mathrm{~mm}$, side-alternating) with an additional load of only $15 \%$ of the participant's body weight, and this regimen clearly failed to produce any benefit.

By contrast, a combination of resistive and vibration exercise has been tested in the Berlin Bed Rest (BBR) study, with the idea to prevent muscle atrophy and bone loss during 56 days of bed rest (Rittweger et al. 2006). A highly demanding vibration exercise regimen $(f=19$ $25 \mathrm{~Hz}, A=$ variable, side-alternating) was performed 11 times per week, and exercise progression was achieved by increasing the vibration frequency and amplitude. Results show that atrophy of the knee extensor and the plantar flexor muscles was mitigated by the exercise intervention (Blottner et al. 2006; Mulder et al. 2006), and that isometric contraction torque and force, respectively, was well maintained (Blottner et al. 2006; Mulder et al. 2006). Muscle biopsy data suggested maintenance of myofibre size in the vastus lateralis, and even an increase in soleus muscle, whilst myofibres shrunk in both muscles in the control group (Blottner et al. 2006). Interestingly, the preservation of knee extension torque was associated with an increase in EMG amplitude (Mulder et al. 2007a), suggesting a specific adaptation to the exercise modality that was most likely due to enhanced central nervous motoneurone excitability. On other hand, there was a decrease within the muscle fibres in ryanodine receptor-1 (RyR1) density, and probably also in RyR1 channel open probability at the end of bed rest in the control, but not in the training group (Salanova et al. 2008), suggesting peripheral alterations in excitability as well. As for the leg muscles, resistive vibration exercise had positive effects for the back extensor muscles, as their atrophy, as well as spinal lengthening and intervertebral disk swelling were all significantly mitigated, though not entirely prevented, in the training group (Belavy et al. 2008).

Moreover, resistive vibration training effectively counteracted fatigability during isometric knee extension, mainly by improving muscular perfusion (Mulder et al. 2007b). In relation to blood flow, resistive vibration training was also found to counteract the reduction in femoral artery diameter (Bleeker et al. 2005). However, the exercise intervention failed to prevent an exaggeration of the vasodilation in response to flow or to nitroglycerine (Bleeker et al. 2005), which both are mediated by nitric oxide. Finally, resistive vibration training likewise failed to prevent decreases in popliteal vein capacitance (van Duijnhoven et al. 2008), suggesting that the training modality may not fully safeguard orthostatic tolerance.

In summary, data available from the BBR study suggest that the combined countermeasure (vibration/resistive exercise) was highly effective to preserve muscular volume and force (and likewise bone mass, Rittweger et al. unpublished data). One should be clear about the fact that the training intervention in the BBR study encompassed vibration in combination with resistive exercise, and that, accordingly, it cannot be determined what has been the specific contribution by the vibration. Both for muscle and bone, however, this countermeasure does not simply 
effectuate a status quo, but rather leads to specific adaptive processes in response to the challenge imposed by the training (Armbrecht et al. 2009).

\section{Clinical application}

It seems clear from the above that vibration induces specific responses in the body that could potentially be exploited for therapeutic purposes. The following sections give a brief overview of the currently available evidence for such clinical applications.

Improving muscular frailty

Muscular frailty is a hallmark of ageing (Runge et al. 2004), and training seems to be an appropriate means to counteract, at least partly, the debilitating effects of senescence (Fiatarone et al. 1990; Malbut et al. 2002; Mian et al. 2007).

A number of studies that have been discussed above (see "Neuromuscular adaptation", Table 1) demonstrate that vibration training is more or less equally effective as conventional resistance training (Roelants et al. 2004b; Russo et al. 2003) or a circuit training (Bogaerts et al. 2007a) to enhance muscle strength and peak power in the elderly. Vibration training has been shown to enhance performance in the chair rising test (Runge et al. 2000). However, in another study (see Table 1) the improvements in chair-rising time, timed-up-and-go test and fast walking speed were comparable in response to vibration training and simple squatting exercise (Rees et al. 2007).

In contrast to this, two studies in institutionalized elderly people suggest specific vibration-related benefits. Following 6-weeks training intervention, improvement in timedup-and-go test and in self-assessed quality of life have been reported (Bruyere et al. 2005), and another study found improvements in leg extension power, timed-up-and-go test and in chair-rising time (Bautmans et al. 2005) to be greater in response to vibration exercise than in response to conventional resistive training. It therefore seems that vibration-specific benefits may be prominent in people who are particularly frail (Bautmans et al. 2005; Bruyere et al. 2005).

Balance and the risk of falls

Muscle power is recognized as one of the risk factors for falls in the elderly, as is the well-known deterioration of balance control (Curb et al. 2006). Various exercise interventions have been shown to improve balance function (Orr et al. 2008; Taube et al. 2008; Wong and Lan 2008) and subsequently the risk of falls (Carter et al. 2001). It seems possible, therefore, that positive effects might also be achieved through vibration exercise.

As discussed above (see "Posture and stance"), muscle, tendon or platform vibration, all have immediate effects upon the human postural control system. One might therefore expect that vibration, as an interfering stimulus, should lead to an immediate deterioration of balance (Oullier et al. 2008). It seems, however, that the mode of vibration application, as well as people's age need to be considered. For example, white-noise vibration, low-pass filtered at $100 \mathrm{~Hz}$ and administered through insoles to the foot, has been shown to reduce, rather than to body sway in young (Priplata et al. 2003). The effect was even more pronounced in elderly participants (Priplata et al. 2003), which has lead the authors to speculate that insole-vibration could be used to prevent falls in the elderly.

Focussing on studies that have investigated vibration as an exercise modality, there seems to be an acute reduction in postural sway (Torvinen et al. 2002a), which, however, does not translate into any persistent changes after an 8months training program in young women (Torvinen et al. 2003). In elderly people, several studies have reported specific benefits in response to whole body vibration training, including improvement in balance (Bogaerts et al. 2007b; Bruyere et al. 2005; Kawanabe et al. 2007; Rees et al. 2008) and gait speed (Bruyere et al. 2005; Kawanabe et al. 2007), both of which are independent predictors of the risk to fall in the elderly. However, future studies are required to document the latter effect.

Is the response to vibration exercise affected by age?

Vibration exercise is often advocated for training in the elderly. However, the question arises in how far the response to vibration exercise will be affected by age. Whilst the magnitude of the vibration-induced reflex contraction seems to be comparable in young and older people (Quoniam et al. 1995), the inhibition of stretch reflexes (Burke et al. 1996) and of the H-reflex (Butchart et al. 1993) seems to be much less pronounced in the elderly. Likewise, the vibration-induced oxygen uptake is mitigated in the elderly (Cochrane et al. 2008a), but the Jendrassik manoeuvre is equally ineffective to enhance vibrationinduced oxygen uptake in old and in young people (Cochrane et al. 2008a). It therefore seems that acute neurophysiological responses to vibration (except for the reflex contraction) are blunted at old age. However, it is unclear whether this is due to neuro-muscular effects, or whether, for example, the age-related reduction in the vibration-induced oxygen uptake is commensurate to the age-related decline in muscle power (Rittweger et al. 2009a). 
Pain

It has classically been found that vibration exposure causes lower back pain (Fishbein and Salter 1950), and engineers and occupational doctors therefore try to reduce it wherever possible (see "Safety aspects"). However, there is evidence to suggest that vibration, when performed as an exercise modality rather than in an occupational context, can alleviate rather than aggravate chromic back pain (Iwamoto et al. 2005; Rittweger et al. 2002b). Interestingly, the often held view that back pain is primarily caused by muscle weakness is contradicted by the finding of equal pain alleviation in the group that performed lumbar extension exercise and in the group that performed vibration exercise (Rittweger et al. 2002b). An alternative mode of explanation could be the genuine analgesic by vibration itself (Tardy-Gervet et al. 1993) to suppress acute (Ekblom and Hansson 1982) and chronic pain (Lundeberg et al. 1984).

Accordingly, vibration therapy seems to lead to longterm remission in many cases (Lundeberg 1984). It is held by most authors that vibration-induced pain relief is best explained by the gate-control theory of pain (Melzack and Wall 1965), which proclaims that fast conducting somatosensory afferents can block poorly myelinated nociceptive afferents at spinal level. Transcutaneous electrical nerve stimulation (TENS), which is used in many clinical centres, is also usually explained by the gate-control theory. Very interestingly, however, the combination of TENS and vibration seems to have larger effects than either of them alone (Guieu et al. 1991), making a common mechanism somewhat unlikely.

Potentially, vibration-induced pain relief may involve supra-spinal mechanisms (Gay et al. 2007), as passive vibration can improve the range of motion and reduce pain severity in complex regional pain syndrome type I, formerly known as reflex sympathetic dystrophy syndrome or Sudeck's atrophy. This disorder is thought to be caused by impaired sensori-motor integration, and it therefore seems to involve supraspinal mechanisms. Finally, vibration in combination with conventional exercise has been found beneficial to reduce pain and fatigue in women with fibromyalgia (Alentorn-Geli et al. 2008), a disorder characterized by exaggerated pain sensation and unusual fatigue. This is important information, as there is currently no effective treatment to fibromyalgia.

\section{Central nervous disorders}

Vibration exercise has been applied also in patients with central nervous disorders. After stroke, for example, maximal voluntary knee extension torque was found to increase following six-1-min bouts of vibration exercise
( $f=20 \mathrm{~Hz}, A=2.5 \mathrm{~mm}$, synchronous) (Tihanyi et al. 2007), but not following static squatting without vibration. The enhanced muscular force and power generation was associated with enhanced EMG amplitude, suggesting central facilitation. Future studies need to test whether this effect can be exploited in the rehabilitation of stroke patients. Another study in stroke patients reports acute reduction in body sway following whole body vibration ( $f=30 \mathrm{~Hz}, A=1.5 \mathrm{~mm}$, synchronous) (van Nes et al. 2004), again suggesting possible benefits for these patients known to have an exaggerated risk of falls and fractures (Sato et al. 2005).

One might also wonder whether muscle vibration could be a means of inducing muscular contractions in patients with spinal cord injury, as a possible alternative to functional electrical stimulation. Indeed, tendon vibration seems to enhance voluntary contractions, at least in some patients (Ribot-Ciscar et al. 2003). However, only half of the patients tested showed the expected elbow extension upon vibration of the triceps brachii muscle, whilst in the others elbow extension was elicited upon vibration of the biceps brachii muscle. This surprising finding is probably due to selective atrophy of the triceps brachii muscle in some patients, and also to altered spinal reflex circuits. These findings suggest that vibration might indeed cause some muscle training effects, but that control of the elicited contractions is not straightforward.

Finally, in patients with Parkinson's disease (PD), acute whole body vibration $(f=6 \mathrm{~Hz}, A=1.5 \mathrm{~mm}$, random) has been found to reduce body sway (Turbanski et al. 2005) and to reduce tremor and rigidity (Haas et al. 2006). Very similarly, acute whole body vibration $(f \geq 1 \mathrm{~Hz}$, $A=3 \mathrm{~mm}$, random) has been found to reduce body sway and the timed-up-and-go time in patients with multiple sclerosis (Schuhfried et al. 2005). Although these studies only involved small sample sizes and only investigated acute effects, they may constitute first hints for the efficacy of whole body vibration in progressive neurological these diseases.

\section{Paediatric rehabilitation}

Earlier studies found improvement of upper body posture by vibratory tendon stimulation in children with cerebral palsy (Redon-Zouiteni et al., cited after Wierzbicka et al. 1998). More recently, Schönau et al. (2008) have applied whole body vibration exercise on a tilting table, with an integral physiotherapeutic approach, in children who were not able to stand by themselves as a result of different disorders such as osteogenesis imperfecta, spina bifida and cerebral palsy (Semler et al. 2007). It was found that patients improved in their functional abilities, which also led to greater independence in almost all cases (Semler 
et al. 2008). These results are very encouraging, in particular because even small improvements can be of great importance in these paediatric patients.

\section{Orthopaedic rehabilitation}

In addition to the acute vibration exercise effects upon knee stabilization (Melnyk et al. 2008), a recent study suggests that vibration training can be helpful in the rehabilitation after replacement of the anterior cruciate ligament (ACL) by enhancing the accuracy of knee joint proprioception (Moezy et al. 2008). Interestingly, the improvement in knee proprioception was equally large or even larger in the nonoperated side as compared to the operated side, implying that the benefits were of more general nature, rather than specific to the ACL graft.

\section{Type-2 diabetes}

As discussed above, acute whole body vibration exercise leads to a decrease in plasma glucose levels, suggesting an enhanced glucose flux into the muscle (Di Loreto et al. 2004). Accordingly, a recent study demonstrates improved glucose tolerance in type-2 diabetic patients as a result of a 9 weeks training intervention (Baum et al. 2007) -an effect that is certainly worth to follow up in future studies.

\section{Safety aspects}

ISO 2631-1 (1997) defines the limits of vibration that people can be expected to tolerate in industrial exposure (see Fig. 5). There are three different limits defined by the ISO 2631-1 standard, namely for comfort, performance proficiency and for safety. Each of these limits is determined by a combination of frequency, direction and time of exposure as well as $a_{\mathrm{RMS}}$ of the actuator. The time limit in relation to safety is assumed to be twice as long as the time limit for performance proficiency.

The important question arises in how far the ISO 2631-1 standard is applicable when vibration is applied as a means of exercise and rehabilitation. Notably, ISO 2631-1 has been based on data obtained in aircraft pilots and drivers (ISO 1997), i.e. for vibration application through the buttocks. The detrimental vibration effects in this situation are therefore given by the vertebral column's and the internal organs' tolerance to vibration. As discussed above (see "The Resonator"), however, the legs help to damp vibration transmission to the trunk. It is obvious that the legs themselves are much more tolerant to vibration exposure than the trunk and head.

On the one hand, ISO 2631-1 levels are certainly too generous for certain groups of patients, such as e.g. acute
ISO 2361-1 Safety Limits for Vertical Sinusoidal Vibration

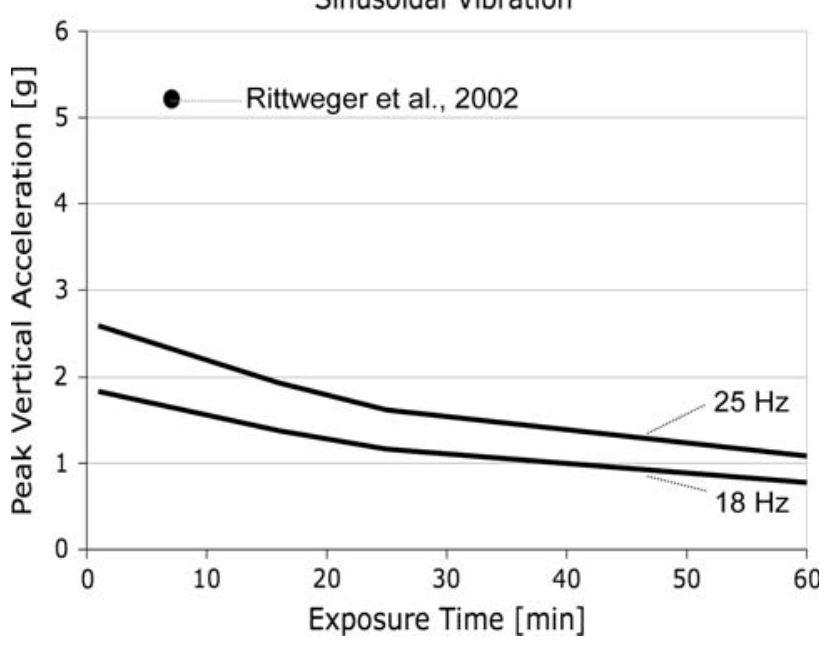

Fig. 5 Safety limits for vertical sinusoidal vibration exposure at $18 \mathrm{~Hz}$ and at $25 \mathrm{~Hz}$, as defined by the ISO 2361-1 standard. The ISO 2361-1 safety-limit for $18 \mathrm{~Hz}$ has been compared to the exposure in a study by Rittweger et al. (2002b), in which whole body vibration ( $f=18 \mathrm{~Hz}, A=6 \mathrm{~mm}$, side-alternating) has been practiced for $7 \mathrm{~min}$ per day by patients with chronic lower back pain. Patients reported significant pain alleviation as a result of the intervention, despite the fact that vibration exposure exceeded the ISO 2361-1 safety-limit by threefold. Moreover, ISO 2361-1 permits greater values for $25 \mathrm{~Hz}$ than for $18 \mathrm{~Hz}$, although perceived exertion in whole body vibration exercise is greater for $25 \mathrm{~Hz}$ than for $18 \mathrm{~Hz}$ vibration. It is apparent, therefore, that ISO 2361-1 limits cannot be transferred to whole body vibration exercise in a straightforward way

trauma patients. On other hand, scientific evidence shows that whole body vibration in excess of allowed ISO 2631-1 levels can relieve back pain in chronical lower back pain sufferers (Rittweger et al. 2002b) — despite the fact that vibration has traditionally been regarded as a cause of, rather than a cure for back pain (see Fig. 5). Moreover, vibrations well above the ISO 2631-1 safety levels are common in sports such as skiing (Spitzenpfeil and Mester 1997). It therefore seems that standards have to be modified to consider exposure to vibration in rehabilitative medicine and exercise. Before such new standards are available, the following paragraphs may give some guidance in order to adopt reasonable safety margins.

\section{Vibration transmission}

We have to bear in mind that shock and vibration are potentially harmful, in particular to the soft tissue organs within the head and the chest. The trunk itself has fairly constant transmission characteristics for frequencies between 5 and $50 \mathrm{~Hz}$, which, however, can be changed by posture (Griffin 1990; Pope et al. 1990; Pradko et al. 1967). Quite importantly, Hinz and Seidel report transmissibility values of $\sim 2$ at the head and of 3 at the shoulder for 
vibration frequencies between 4 and $5 \mathrm{~Hz}$ in seated humans (Hinz and Seidel 1987), thus confirming the occurrence of amplitude amplification in this frequency range.

For the lower extremity, shock transmissibility with straight knees was found to be $>1$ for frequencies around $2 \mathrm{~Hz}$, but values drop to $<0.5$ for frequencies above $5 \mathrm{~Hz}$ (Lafortune et al. 1996). Importantly, shock transmission is reduced by knee flexion for all frequencies (Lafortune et al. $1996)$. For whole body vibration $\left(a_{\text {Peak }}=0.1 \mathrm{~g}\right.$, synchronous), Rubin et al. (2003) report transmissibility values up to 1.3 for frequencies below $20 \mathrm{~Hz}$ and with straight knees, and Kiiski et al. (2008) report transmissibility values of up to $\approx 5$, depending on the vibration amplitude. With the knees flexed to $20^{\circ}$, however, transmissibility was reduced to 0.5 for frequencies below $20 \mathrm{~Hz}$, and even further to values around 0.25 for frequencies above $20 \mathrm{~Hz}$ (Rubin et al. 2003). For the spine, Rubin et al. (2003) give transmissibility values between 0.6 and 0.8 , almost irrespective of frequency and posture, but Kiiski et al. (2008) found values of up to 5 for transmissibility in erect posture with $10 \mathrm{~Hz}$ vibration.

Vibration transmissibility to the head and trunk can be reduced by knee flexion (Abercromby et al. 2007b). More precisely, transmissibility was halved by increasing the knee flexion angle from $10^{\circ}$ to $30^{\circ}$ in that study. One has to expect further attenuation of the vibratory stimulus when posing the body weight on the forefoot and thus adding the ankle joint to the resonator (see (Wakeling et al. 2002) and Fig. 4b). Moreover, vibration transmissibility to the head was 2-3 times smaller in side-alternating than in synchronous whole body vibration (Abercromby et al. 2007b).

In summary, resonance can occur within the trunk at vibration frequencies around $5 \mathrm{~Hz}$, and in the lower extremity at frequencies below $20 \mathrm{~Hz}$. Although it is unknown whether resonance in whole body vibration exercise is large enough to cause any actual harm, it would be prudent not to use frequencies around and below $5 \mathrm{~Hz}$, and to exercise specific caution with frequencies below $20 \mathrm{~Hz}$. Alteration of posture, e.g. by posing more body weight on the forefoot or flexing the knees, can diminish vibration transmission considerably, and using side-alternating rather than synchronous vibration can further reduce transmission to the trunk and head. These are general recommendations, which, however, will allow a fairly accurate control of vibration exposure and transmission on a practical basis. Given the potential for damage, the above information ought to be given to all novices, and un-authorized access to vibration platforms should be prevented.

Vibration white finger disease

Occupational medicine has identified vibration in hand held tools as the cause of vibration white finger disease
(Pelmear 1974), which is the vascular component of the hand-arm vibration syndrome (Gemne et al. 1987). Exposure to hand-transmitted vibration, typically over several years (Brubaker et al. 1983), causes a secondary Raynaud's phenomenon (Dandanell and Engstrom 1986), with poor perfusion, particularly in a cold environment (Taylor et al. 1986). The disease can be debilitating and lead to impaired sensory and motor function in the affected hand (Necking et al. 2002). It is nowadays believed that the vibration white finger disease is caused by chronic mechanical damage of cutaneous nerve fibres (Goldsmith et al. 1994; Lundborg et al. 1990), which physiologically are involved in the axon reflex (Bruce 1913) and thus promote vasodilation through release of endothelin-1 and histamin (Dowd et al. 1998). This launches a cascade of dysregulatory events, including decreased $\alpha_{2}$ and increased $\alpha_{1}$ susceptibility, finally emanating the full picture of the disorder (for a review see Stoyneva et al. (2003)). In addition to the damage of afferent nerves, there is also evidence for muscular fibre type grouping, compatible with efferent nerve damage and re-innervation (Necking et al. 2004).

It is unclear whether an equivalent to the vibration white finger disease can also occur in the lower extremity. One might speculate that the feet are naturally more exposed to locomotion-related shock absorption (Glasheen and McMahon 1995), and thereby perhaps more resilient to damage caused by it. Nevertheless, it would be prudent to consider the recommendations defined for occupational exposure to hand-held vibration tools, set out in ISO 5349 (2001). As stated in the annex of ISO 5349, daily exposure over $8 \mathrm{~h}$ with $a_{\mathrm{RMS}} \leq 2 \mathrm{~m} / \mathrm{s}^{2}$ will rarely ensue the disorder (Mansfield 2004). To give an example for whole body vibration exercise, and assuming complete vibration transmission from the platform to the foot, this would limit the time of daily exposure for a setting of $f=30 \mathrm{~Hz}$ and $A=5 \mathrm{~mm}$ to $\approx 460 \mathrm{~s}$, or just under $8 \mathrm{~min}$. However, vibration transmissibility between platform and ankle can sometimes be greater than 1 (Kiiski et al. 2008), probably depending on posture, anatomical, biomechanical and neuromuscular characteristics of the individual as well as on the type of vibration device (e.g. side-alternating or synchronous) (Abercromby et al. 2007b). It is therefore possible that some individuals, who practice vibration in excess of those daily limits over years put themselves at risk to develop a vibration white toe disease-future research is clearly needed to monitor that possibility.

\section{Conclusions}

Whilst vibration exposure has traditionally been regarded as perilous only, it is now seen as potentially beneficial in certain areas of sports, exercise, rehabilitation and 
preventive medicine. Although not all the claims made by manufacturers may withstand scientific scrutiny, there is an emerging profile of application of vibration as an exercise modality. Physiologically, the specific advantages of that modality may arise (1) from comparatively large acceleration levels that can still be reasonably controlled, (2) from the controlled transfer of mechanical energy to the human body, (3) from the large number of repetitive cycles within short periods of time, and (4) from the specific effects deployed via muscle spindles and fast adapting mechanoreceptors.

For sports, vibration exercise seems to lead to a rapid and energy-sparing warm-up effect, and it may help to improve flexibility. Vibration seems to be a viable training method to increase jump height and muscle power (Table 1), but research is still inconclusive as to whether the same could not be achieved by traditional resistive exercise, albeit with longer training times.

As to medicine, there is already good evidence to suggest improvement of balance in frail elderly and possibly also in patients with central nervous disorders by whole body vibration exercise. There may also be a beneficial effect by vibration training upon muscle power, in particular in very frail elderly people (Table 1). Future research should address whether the latter two effects can be strong enough to reduce the risk of falls in the elderly population. Moreover, literature unanimously supports the use of vibration to reduce pain perception (but not delayed onset muscle soreness), and for whole body vibration to improve chronic lower back pain. There is also substantial evidence to suggest that bones can be affected by vibration, although the exact mechanism is currently unclear. Strictly speaking, the evidence is somewhat weaker for the high-magnitude approach than for the low-magnitude approach, but it is difficult to see how the latter can work and not the former. Future possible indications for vibration exercise include prevention of ACL trauma and its rehabilitation, type- 2 diabetes, and stress incontinence (V. Viereck, personal communication).

However, clearly more research is needed in order to better understand the specific therapeutic potential of vibration as an exercise model. Moreover, there seems to be a certain need for studies to assess any potential longterm risks. However, with appropriate introduction to the exercise modality, vibration exercise seems to be reasonably safe for most people.

Acknowledgment I would wish to express my gratitude to Dag Linarsson for inviting me to write this article-complying with his request has been even more enjoyable (but also more exhaustive) than anticipated. I am also grateful to friends and colleagues in the IRM Institute up in Manchester, whose presence compensates me for the daily driving hour(s) on the M6 and on the trains. Most importantly, thanks to the two Hans' (Schiessl \& Degens), who are entirely different characters, but equally good characters, and who hopefully will continue to en-Hans me.

\section{References}

Abercromby AF, Amonette WE, Layne CS, McFarlin BK, Hinman MR, Paloski WH (2007a) Variation in neuromuscular responses during acute whole-body vibration exercise. Med Sci Sports Exerc 39:1642-1650

Abercromby AF, Amonette WE, Layne CS, McFarlin BK, Hinman MR, Paloski WH (2007b) Vibration exposure and biodynamic responses during whole-body vibration training. Med Sci Sports Exerc 39:1794-1800

Alentorn-Geli E, Padilla J, Moras G, Lazaro Haro C, Fernandez-Sola J (2008) Six weeks of whole-body vibration exercise improves pain and fatigue in women with fibromyalgia. J Altern Complement Med (NY) 14:975-981

Arcangel CS, Johnston R, Bishop B (1971) The achilles tendon reflex and the H-response during and after tendon vibration. Phys Ther 51:889-905

Armbrecht G, Belavy DL, Gast U, Bongrazio M, Touby F, Beller G, Roth HJ, Perschel FH, Rittweger J, Felsenberg D (2009) Resistive vibration exercise attenuates bone and muscle atrophy in 56-days of bed-rest: whole body DXA and biochemical markers of bone metabolism. Osteoporos Int PMID: 19536451

Atha J, Wheatley DW (1976) Joint mobility changes due to low frequency vibration and stretching exercise. Br J Sports Med $10: 26-34$

Baum K, Votteler T, Schiab J (2007) Efficiency of vibration exercise for glycemic control in type 2 diabetes patients. In J Med Sci 4:159-163

Bautmans I, Van Hees E, Lemper JC, Mets T (2005) The feasibility of Whole Body Vibration in institutionalised elderly persons and its influence on muscle performance, balance and mobility: a randomised controlled trial [ISRCTN62535013]. BMC Geriatri $5: 17$

Bazett-Jones DM, Finch HW, Dugan EL (2008) Comparing the effects of various whole-body vibration accelerations on countermovement jump performance. J Sports Sci Med 7:144

Belavy DL, Hides JA, Wilson SJ, Stanton W, Dimeo FC, Rittweger J, Felsenberg D, Richardson CA (2008) Resistive simulated weightbearing exercise with whole body vibration reduces lumbar spine deconditioning in bed-rest. Spine 33:E121-E131

Bergenheim M, Ribot-Ciscar E, Roll JP (2000) Proprioceptive population coding of two-dimensional limb movements in humans: I. Muscle spindle feedback during spatially oriented movements. Exp Brain Res 134:301

Berschin G, Schmiedeberg I, Sommer H-M (2003) Zum Einsatz von Vibrationskrafttraining als spezifisches Schnellkrafttrainingsmittel in Sportspielen. Leistungssport 4:11-13

Bianconi R, van der MJ (1963) The response to vibration of the end organs of mammalian muscle spindles. J Neurophysiol 26:177190

Bleeker MW, De Groot PC, Rongen GA, Rittweger J, Felsenberg D, Smits P, Hopman MT (2005) Vascular adaptation to deconditioning and the effect of an exercise countermeasure: results of the Berlin Bed Rest study. J Appl Physiol 99:1293-1300

Blottner D, Salanova M, Puttmann B, Schiffl G, Felsenberg D, Buehring B, Rittweger J (2006) Human skeletal muscle structure and function preserved by vibration muscle exercise following 55 days of bed rest. Eur J Appl Physiol 97:261-271

Bogaerts A, Delecluse C, Claessens AL, Coudyzer W, Boonen S, Verschueren SM (2007a) Impact of whole-body vibration training versus fitness training on muscle strength and muscle 
mass in older men: a 1-year randomized controlled trial. J Gerontol A Biol Sci Med Sci 62:630-635

Bogaerts A, Verschueren S, Delecluse C, Claessens AL, Boonen S (2007b) Effects of whole body vibration training on postural control in older individuals: a 1 year randomized controlled trial. Gait Posture 26:309-316

Bongiovanni LG, Hagbarth KE (1990) Tonic vibration reflexes elicited during fatigue from maximal voluntary contractions in man. J Physiol (Lond) 423:1

Bongiovanni LG, Hagbarth KE, Stjernberg L (1990) Prolonged muscle vibration reducing motor output in maximal voluntary contractions in man. J Physiol (Lond) 423:15

Borg G, Borg G (1976) Simple rating methods for estimation of perceived exertion. Physical work and effort. Pergamon Press, Oxford, p 39

Bosco C, Cardinale M, Colli R, Tihanyi J, SPv Duvillard, Viru A (1998a) The influence of whole body vibration on the mechanical behaviour of skeletal muscle. Biol Sport 153:157-164

Bosco C, Cardinale M, Tsarpela O, Colli R, Tihanyi J, von Duvillard SP, Viru A (1998b) The influence of whole body vibration on jumping performance. Biology of Sport 15:157-164

Bosco C, Cardinale M, Tsarpela O (1999a) Influence of vibration on mechanical power and electromyogram activity in human arm flexor muscles. Eur J Appl Physiol 79:306

Bosco C, Colli R, Introini E, Cardinale M, Tsarpela O, Madella A, Tihanyi J, Viru A (1999b) Adaptive responses of human skeletal muscle to vibration exposure. Clin Physiol 19:183

Bosco C, Iacovelli M, Tsarpela O, Cardinale M, Bonifazi M, Tihanyi J, Viru M, De Lorenzo A, Viru A (2000) Hormonal responses to whole-body vibration in men. Eur J Appl Physiol 81:449

Brown MC, Engberg I, Matthews PB (1967) The relative sensitivity to vibration of muscle receptors of the cat. J Physiol 192:773800

Brubaker RL, Mackenzie CJ, Eng PR, Bates DV (1983) Vibration white finger disease among tree fellers in British Columbia. J Occup Med 25:403-408

Bruce AN (1913) Vaso-dilator axon reflexe. Q J Exp Physiol 6:339_ 354

Bruyere O, Wuidart MA, Di Palma E, Gourlay M, Ethgen O, Richy F, Reginster JY (2005) Controlled whole body vibration to decrease fall risk and improve health-related quality of life of nursing home residents. Arch Phys Med Rehabil 86:303-307

Burke D, Hagbarth KE, Lofstedt L, Wallin BG (1976) The responses of human muscle spindle endings to vibration during isometric contraction. J Physiol (Lond) 261:695

Burke JR, Schutten MC, Koceja DM, Kamen G (1996) Agedependant effects on muscle vibration and the Jendrassik Maneuver on the Patellar Tendon Reflex. Arch Phys Med Rehabil 77:604

Butchart P, Farquhar R, Part NJ, Roberts RC (1993) The effect of age and voluntary contraction on presynaptic inhibition of soleus muscle Ia afferent terminals in man. Exp Physiol 78:235-242

Cafarelli E, Kostka CE (1981) Effect of vibration on static force sensation in man. Exp Neurol 74:331-340

Cafarelli E, Layton-Wood J (1986) Effect of vibration on force sensation in fatigued muscle. Med Sci Sports Exerc 18:516-521

Calvisi V, Angelozzi M, Franco A, Mottola L, Crisostomi S, Corsica C, Ferrari M, Quaresima V (2006) Influence of whole-body vibration static exercise on quadriceps oxygenation. Adv Exp Med Biol 578:137-141

Cardinale M, Lim J (2003) Electromyography activity of vastus lateralis muscle during whole-body vibrations of different frequencies. J Strength Cond Res 17:621-624

Cardinale M, Rittweger J (2006) Vibration exercise makes your muscles and bones stronger: fact or fiction? J Br Menopause Soc $12: 12-18$
Cardinale M, Leiper J, Erskine J, Milroy M, Bell S (2006) The acute effects of different whole body vibration amplitudes on the endocrine system of young healthy men: a preliminary study. Clin Physiol Funct Imaging 26:380-384

Cardinale M, Ferrari M, Quaresima V (2007) Gastrocnemius medialis and vastus lateralis oxygenation during whole-body vibration exercise. Med Sci Sports Exerc 39:694-700

Cardinale M, Soiza RL, Leiper JB, Gibson A, Primrose WR (2008) Hormonal responses to a single session of whole body vibration exercise in elderly individuals. $\mathrm{Br} \mathrm{J}$ Sports Med PMID: 18413339

Carter ND, Kannus P, Khan KM (2001) Exercise in the prevention of falls in older people: a systematic literature review examining the rationale and the evidence. Sports Med 31:427-438

Cochrane DJ, Stannard SR (2005) Acute whole body vibration training increases vertical jump and flexibility performance in elite female field hockey players. Br J Sports Med 39:860-865

Cochrane DJ, Legg SJ, Hooker MJ (2004) The short-term effect of whole-body vibration training on vertical jump, sprint, and agility performance. J Strength Cond Res 18:828-832

Cochrane DJ, Sartor F, Winwood K, Stannard SR, Narici MV, Rittweger J (2008a) A comparison of the physiologic effects of acute whole-body vibration exercise in young and older people. Arch Phys Med Rehabil 89:815-821

Cochrane DJ, Stannard SR, Sargeant AJ, Rittweger J (2008b) The rate of muscle temperature increase during acute whole-body vibration exercise. Eur J Appl Physiol 103:441-448

Cochrane DJ, Loram ID, Stannard SR, Rittweger J (2009) Changes in joint angle, muscle-tendon complex length, muscle contractile tissue displacement and modulation of EMG activity during acute whole-body vibration Muscle Nerve PMID: 19618430

Cole SH (1978) The vertical transmission of impulse energy through the seated human. University of Technology, Loughborough

Cook DI, Lingard JM, Wegman EA, Young JA (2000) Ernährung, Energiehaushalt und Stoffwechsel (Nutrition, Energy Balance and Metabolism). In: Klinke R, Silbernagl S (eds) Lehrbuch der Physiologie (Textbook of Physiology). Thieme, Stuttgart

Cordo P, Gandevia SC, Hales JP, Burke D, Laird G (1993) Force and displacement-controlled tendon vibration in humans. Electroencephalogr Clin Neurophysiol 89:45-53

Corpas E, Harman SM, Blackman MR (1993) Human growth hormone and human aging. Endocr Rev 14:20-39

Cronin J, Nash M, Whatman C (2008) The acute effects of hamstring stretching and vibration on dynamic knee joint range of motion and jump performance. Phys Ther Sport 9:89-96

Curb JD, Ceria-Ulep CD, Rodriguez BL, Grove J, Guralnik J, Willcox BJ, Donlon TA, Masaki KH, Chen R (2006) Performance-based measures of physical function for high-function populations. J Am Geriatr Soc 54:737-742

Curtis DR, Eccles JC (1960) Synaptic action during and after repetitive stimulation. J Physiol 150:374-398

Dadebo B, White J, George KP (2004) A survey of flexibility training protocols and hamstring strains in professional football clubs in England. Br J Sports Med 38:388-394

Dandanell R, Engstrom K (1986) Vibration from riveting tools in the frequency range $6 \mathrm{~Hz}-10 \mathrm{MHz}$ and Raynaud's phenomenon. Scand J Work Environ Health 12:338-342

De Gail P, Lance JW, Neilson PD (1966) Differential effects on tonic and phasic reflex mechanisms produced by vibration of muscles in man. J Neurol Neurosurg Psychiatry 29:1

De Ruiter CJ, De Haan A (2000) Temperature effect on the force/ velocity relationship of the fresh and fatigued human adductor pollicis muscle. Pflugers Arch 440:163-170

De Ruiter CJ, Schilperoort J, van Raak S, Hollander AP, de Haan A (2003a) The effects of 11 weeks whole body vibration training 
on jump height, contractile properties and activation of human knee extensors. Eur J Appl Physiol 90:595-600

De Ruiter CJ, Van Der Linden RM, Van Der Zijden MJ, Hollander AP, de Haan A (2003b) Short-term effects of whole-body vibration on maximal voluntary isometric knee extensor force and rate of force rise. Eur J Appl Physiol 88:472

Delecluse C, Roelants M, Verschueren S (2003) Strength increase after whole-body vibration compared with resistance training. Med Sci Sports Exerc 35:1033-1041

Delecluse C, Roelants M, Diels R, Koninckx E, Verschueren S (2005) Effects of whole body vibration training on muscle strength and sprint performance in sprint-trained athletes. Int $\mathrm{J}$ Sports Med 26:662-668

Di Loreto C, Ranchelli A, Lucidi P, Murdolo G, Parlanti N, De Cicco A, Tsarpela O, Annino G, Bosco C, Santeusanio F, Bolli GB, De Feo P (2004) Effects of whole-body vibration exercise on the endocrine system of healthy men. J Endocrinol Invest 27:323-327

Doshi SN, Naka KK, Payne N, Jones CJ, Ashton M, Lewis MJ, Goodfellow J (2001) Flow-mediated dilatation following wrist and upper arm occlusion in humans: the contribution of nitric oxide. Clin Sci (Lond) 101:629-635

Dowd PM, Goldsmith PC, Chopra S, Bull HA, Foreman JC (1998) Cutaneous responses to endothelin- 1 and histamine in patients with vibration white finger. J Invest Dermatol 110:127-131

Egan CE, Espie BH, McGrann S, McKenna KM, Allen JA (1996) Acute effects of vibration on peripheral blood flow in healthy subjects. Occup Environ Med 53:663-669

Ekblom A, Hansson P (1982) Effects of conditioning vibratory stimulation on pain threshold of the human tooth. Acta Physiol Scand 114:601-604

Eklund G (1969) Influence of muscle vibration on balance in man. A preliminary report. Acta Soc Med Ups 74:113

Eklund G (1972) General features of vibration-induced effects on balance. Ups J Med Sci 77:112

Eklund G (1973) Further studies of vibration-induced effects on balance. Ups J Med Sci 78:65

Erskine J, Smillie I, Leiper J, Ball D, Cardinale M (2007) Neuromuscular and hormonal responses to a single session of whole body vibration exercise in healthy young men. Clin Physiol Funct Imaging 27:242-248

Falempin M, In-Albon SF (1999) Influence of brief daily tendon vibration on rat soleus muscle in non-weight-bearing situation. J Appl Physiol 87:3-9

Farkkila M, Pyykko I, Korhonen O, Starck J (1980) Vibrationinduced decrease in the muscle force in lumberjacks. Eur J Appl Physiol Occup Physiol 43:1-9

Fiatarone MA, Marks EC, Ryan ND, Meredith CN, Lipsitz LA, Evans WJ (1990) High-intensity strength training in nonagenarians. Effects on skeletal muscle. JAMA 263:3029

Fishbein WI, Salter LC (1950) The relationship between truck and tractor driving and disorders of the spine and supporting structures; report of a survey. Ind Med Surg 19:444-445

Forsythe JA, Jiang BH, Iyer NV, Agani F, Leung SW, Koos RD, Semenza GL (1996) Activation of vascular endothelial growth factor gene transcription by hypoxia-inducible factor 1 . Mol Cell Biol 16:4604-4613

Forth KE, Layne CS (2008) Neuromuscular responses to mechanical foot stimulation: the influence of loading and postural context. Aviat Space Environ Med 79:844-851

Gabriel DA, Basford JR, An KN (2002) Vibratory facilitation of strength in fatigued muscle. Arch Phys Med Rehabil 83:12021205

Garman R, Gaudette G, Donahue LR, Rubin C, Judex S (2007a) Lowlevel accelerations applied in the absence of weight bearing can enhance trabecular bone formation. J Orthop Res 25:732-740
Garman R, Rubin C, Judex S (2007b) Small oscillatory accelerations, independent of matrix deformations, increase osteoblast activity and enhance bone morphology. PLoS ONE 2:e653

Gay A, Parratte S, Salazard B, Guinard D, Pham T, Legre R, Roll JP (2007) Proprioceptive feedback enhancement induced by vibratory stimulation in complex regional pain syndrome type I: an open comparative pilot study in 11 patients. Joint Bone Spine 74:461-466

Gemne G, Pyykko I, Taylor W, Pelmear PL (1987) The Stockholm Workshop scale for the classification of cold-induced Raynaud's phenomenon in the hand-arm vibration syndrome (revision of the Taylor-Pelmear scale). Scand J Work Environ Health 13:275-278

Ghista DN (1982) Human body dynamics: Impact, occupational and athletic aspects. Clarendon Prress, Oxford

Gilhodes JC, Gurfinkel VS, Roll JP (1992) Role of Ia muscle spindle afferents in post-contraction and post- vibration motor effect genesis. Neurosci Lett 135:247

Gillies JD, Lance JW, Neilson PD, Tassinari CA (1969) Presynaptic inhibition of the monosynaptic reflex by vibration. J Physiol (Lond) 205:329

Gilsanz V, Wren TA, Sanchez M, Dorey F, Judex S, Rubin C (2006) Low-level, high-frequency mechanical signals enhance musculoskeletal development of young women with low BMD. J Bone Miner Res 21:1464-1474

Glasheen JW, McMahon TA (1995) Arms are different from legs: mechanics and energetics of human hand- running. J Appl Physiol 78:1280

Goldsmith PC, Molina FA, Bunker CB, Terenghi G, Leslie TA, Fowler CJ, Polak JM, Dowd PM (1994) Cutaneous nerve fibre depletion in vibration white finger. J R Soc Med 87:377-381

Goodwin GM, McCloskey DI, Matthews PB (1972a) Proprioceptive illusions induced by muscle vibration: contribution by muscle spindles to perception? Science 175:1382-1384

Goodwin GM, McCloskey DI, Matthews PB (1972b) The contribution of muscle afferents to kinaesthesia shown by vibration induced illusions of movement and by the effects of paralysing joint afferents. Brain 95:705

Goto K, Takamatsu K (2005) Hormone and lipolytic responses to whole body vibration in young men. Jpn J Physiol 55:279-284

Granit R, Henatsch HD, Steg G (1956) Tonic and phasic ventral horn cells differentiated by post-tetanic potentiation in cat extensors. Acta Physiol Scand 37:114-126

Greaves MW, Sondergaard J (1970) Urticaria pigmentosa and factitious urticaria. Direct evidence for release of histamine and other smooth muscle-contracting agents in dermographic skin. Arch Dermatol 101:418-425

Greene PR, McMahon TA (1979) Reflex stiffness of man's antigravity muscles during kneebends while carrying extra weights. J Biomech 12:881

Griffin MJ (1990) Handbook of human vibration. Academic Press, New York

Guieu R, Tardy-Gervet MF, Roll JP (1991) Analgesic effects of vibration and transcutaneous electrical nerve stimulation applied separately and simultaneously to patients with chronic pain. Can J Neurol Sci 18:113-119

Gusi N, Raimundo A, Leal A (2006) Low-frequency vibratory exercise reduces the risk of bone fracture more than walking: a randomized controlled trial. BMC Musculoskel Disord 7:92

Haas CT, Turbanski S, Kessler K, Schmidtbleicher D (2006) The effects of random whole-body-vibration on motor symptoms in Parkinson's disease. NeuroRehabilitation 21:29-36

Hagbarth KE, Desmedt JE (1973) The effect of muscle vibration in normal man and in patients with motor disease. New Developments in Electromyography and Clinical Neurophysiology. Karger, Basel, p 428 
Hagbarth KE, Eklund G (1966) Motor effects of vibratory stimuli in man. In: Granit R (ed) Nobel symposium I muscular afferents and motor control. Almqvist and Wiksell, Stockholm

Hagbarth KE, Eklund G (1969) The muscle vibrator-a useful tool in neurological therapeutic work. Scand J Rehabil Med $1: 26$

Hagbarth KE, Kunesch EJ, Nordin M, Schmidt R, Wallin EU (1986) Gamma loop contributing to maximal voluntary contractions in man. J Physiol (Lond) 380:575

Hayward LF, Nielsen RP, Heckman CJ, Hutton RS (1986) Tendon vibration-induced inhibition of human and cat triceps surae group I reflexes: evidence of selective Ib afferent fiber activation. Exp Neurol 94:333-347

Henneman E (1985) The size-principle: a deterministic output emerges from a set of probabilistic connections. J ExpBiol 115:105

Herda TJ, Ryan ED, Smith AE, Walter AA, Bemben MG, Stout JR, Cramer JT (2008) Acute effects of passive stretching vs vibration on the neuromuscular function of the plantar flexors. Scand $\mathrm{J}$ Med Sci Sports 19(5):703-713

Hering E, Martin R, Stohrer M (2004) Physik für Ingenieure (Physics for engineers). Springer, Berlin

Hinz B, Seidel H (1987) The nonlinerarity of the human body's dynamic response during sinusoidal whole body vibration. Ind Health 25:169-181

Homma S, Desmedt JE (1973) A survey of Japanese Research on muscle vibration. New Developments in Electromyography and Clinical Neurophysiology. Karger, Basel, p 463

Homma S, Kanda K, Watanabe S (1971) Monosynaptic coding of group Ia afferent discharges during vibratory stimulation of muscles. Jpn J Physiol 21:405-417

Hopkins JT, Fredericks D, Guyon PW, Parker S, Gage M, Feland JB, Hunter I (2008a) Whole body vibration does not potentiate the stretch reflex. Int J Sports Med 30(2):124-129

Hopkins T, Pak JO, Robertshaw AE, Feland JB, Hunter I, Gage M (2008b) Whole body vibration and dynamic restraint. Int J Sports Med 29:424-428

Ishitake T, Miyazaki Y, Ando H, Matoba T (1999) Suppressive mechanism of gastric motility by whole-body vibration. Int Arch Occup Environ Health 72:469-474

ISO (1997) 2361-1. In: Organization IS (ed) Mechanical vibration and shock-evaluation of human exposure to whole body vibration. Geneva, Switzerland

ISO (2001) 5349. In: Organization IS (ed) Mechanical vibrationMeasurement and evaluation of human exposure to handtransmitted vibration. Geneva, Switzerland

Issurin VB, Tenenbaum G (1999) Acute and residual effects of vibratory stimulation on explosive strength in elite and amateur athletes. J Sports Sci 17:177

Issurin VB, Liebermann DG, Tenenbaum G (1994) Effect of vibratory stimulation training on maximal force and flexibility. J Sports Sci 12:561

Ivanenko YP, Talis VL, Kazennikov OV (1999) Support stability influences postural responses to muscle vibration in humans. Eur J Neurosci 11:647-654

Ivanenko YP, Solopova IA, Levik YS (2000) The direction of postural instability affects postural reactions to ankle muscle vibration in humans. Neurosci Lett 292:103-106

Iwamoto J, Takeda T, Sato Y, Uzawa M (2005) Effect of whole-body vibration exercise on lumbar bone mineral density, bone turnover, and chronic back pain in post-menopausal osteoporotic women treated with alendronate. Aging Clin Exp Res 17:157-163

Judex S, Lei X, Han D, Rubin C (2007) Low-magnitude mechanical signals that stimulate bone formation in the ovariectomized rat are dependent on the applied frequency but not on the strain magnitude. J Biomech 40:1333-1339
Kavounoudias A, Roll R, Roll JP (1998) The plantar sole is a 'dynamometric map' for human balance control. Neuroreport 9:3247-3252

Kavounoudias A, Roll R, Roll JP (1999) Specific whole-body shifts induced by frequency-modulated vibrations of human plantar soles. Neurosci Lett 266:181-184

Kavounoudias A, Roll R, Roll JP (2001) Foot sole and ankle muscle inputs contribute jointly to human erect posture regulation. J Physiol 532:869-878

Kawanabe K, Kawashima A, Sashimoto I, Takeda T, Sato Y, Iwamoto J (2007) Effect of whole-body vibration exercise and muscle strengthening, balance, and walking exercises on walking ability in the elderly. Keio J Med 56:28-33

Kerschan-Schindl K, Grampp S, Henk C, Resch H, Preisinger E, Fialka-Moser V, Imhof H (2001) Whole-body vibration exercise leads to alterations in muscle blood volume. Clin Physiol 21:377

Kiiski J, Heinonen A, Jarvinen TL, Kannus P, Sievanen H (2008) Transmission of vertical whole body vibration to the human body. J Bone Miner Res 23:1318-1325

Kindermann W, Schnabel A, Schmitt WM, Biro G, Cassens J, Weber F (1982) Catecholamines, growth hormone, cortisol, insulin, and sex hormones in anaerobic and aerobic exercise. Eur $\mathbf{J}$ Appl Physiol Occup Physiol 49:389-399

Kinser AM, Ramsey MW, O'Bryant HS, Ayres CA, Sands WA, Stone MH (2008) Vibration and stretching effects on flexibility and explosive strength in young gymnasts. Med Sci Sports Exerc 40:133-140

Kjaer M (1998) Adrenal medulla and exercise training. Eur J Appl Physiol Occup Physiol 77:195-199

Klein-Nulend J, Semeins CM, Ajubi NE, Nijweide PJ, Burger EH (1995) Pulsating fluid flow increases nitric oxide (NO) synthesis by osteocytes but not periosteal fibroblasts-correlation with prostaglandin upregulation. Biochem Biophys Res Commun 217:640

Kossev A, Siggelkow S, Schubert M, Wohlfarth K, Dengler R (1999) Muscle vibration: different effects on transcranial magnetic and electrical stimulation. Muscle Nerve 22:946-948

Kossev A, Siggelkow S, Kapels H, Dengler R, Rollnik JD (2001) Crossed effects of muscle vibration on motor-evoked potentials. Clin Neurophysiol 112:453-456

Kouzaki M, Shinohara M, Fukunaga T (2000) Decrease in maximal voluntary contraction by tonic vibration applied to a single synergist muscle in humans. J Appl Physiol 89:1420-1424

Kraemer WJ, Marchitelli L, Gordon SE, Harman E, Dziados JE, Mello R, Frykman P, McCurry D, Fleck SJ (1990) Hormonal and growth factor responses to heavy resistance exercise protocols. J Appl Physiol 69:1442-1450

Kubo K, Kanehisa H, Kawakami Y, Fukunaga T (2001) Influence of static stretching on viscoelastic properties of human tendon structures in vivo. J Appl Physiol 90:520-527

Kvorning T, Bagger M, Caserotti P, Madsen K (2006) Effects of vibration and resistance training on neuromuscular and hormonal measures. Eur J Appl Physiol 96:615-625

Lackner JR (1988) Some proprioceptive influences on the perceptual representation of body shape and orientation. Brain $111(\mathrm{Pt}$ 2):281-297

Lafortune MA, Lake MJ, Hennig EM (1996) Differential shock transmission response of the human body to impact severity and lower limb posture. J Biomech 29:1531-1537

Lance JW, Burke D, Andrews CJ (1973) The reflex effects of muscle vibration. Studies of the tendon jerk irradiation, phasic reflex inhibition and the tonic vibration refex. New Developments in EMG and Clinical Neurophysiology. Karger, Basel, pp 444-462

Lawlor EF (2000) The physical urticarias. In: Leung DYM, Greaves M (eds) Allergic skin disease: a multidisciplinary approach. Informa Health Care, London, pp 195-211 
Lawlor F, Black AK, Breathnach AS, Greaves MW (1989) Vibratory angioedema: lesion induction, clinical features, laboratory and ultrastructural findings and response to therapy. Br J Dermatol 120:93

Layne CS, Forth KE, Baxter MF, Houser JJ (2002) Voluntary neuromuscular activation is enhanced when paired with a mechanical stimulus to human plantar soles. Neurosci Lett 334:75-78

Layne CS, Forth KE, Abercromby AF (2005) Spatial factors and muscle spindle input influence the generation of neuromuscular responses to stimulation of the human foot. Acta Astronaut $56: 809-819$

LeBlanc A, Lin C, Shackelford L, Sinitsyn V, Evans H, Belichenko O, Schenkman B, Kozlovskaya I, Oganov V, Bakulin A, Hedrick T, Feeback D (2000) Muscle volume, MRI relaxation times (T2), and body composition after spaceflight. J Appl Physiol 89:2158

LeBlanc AD, Driscol TB, Shackelford LC, Evans HJ, Rianon NJ, Smith SM, Feeback DL, Lai D (2002) Alendronate as an effective countermeasure to disuse induced bone loss. J Musculoskelet Neuronal Interact 2:335-343

LeBlanc AD, Spector ER, Evans HJ, Sibonga JD (2007) Skeletal responses to space flight and the bed rest analog: a review. J Musculoskelet Neuronal Interact 7:33-47

Lewis T (1924) Vascular reactins of the skin to injury - 1. Reactions to stroking. Heart 2:119-129

Lohman EB 3rd, Petrofsky JS, Maloney-Hinds C, Betts-Schwab H, Thorpe D (2007) The effect of whole body vibration on lower extremity skin blood flow in normal subjects. Med Sci Monit 13:CR71-CR76

Lundberg A, Malmgren K, Schomburg ED (1975) Convergence from $\mathrm{Lb}$, cutaneous and joint afferents in reflex pathways to motoneurones. Brain Res 87:81-84

Lundborg G, Dahlin LB, Hansson HA, Kanje M, Necking LE (1990) Vibration exposure and peripheral nerve fiber damage. J Hand Surg [Am] 15:346-351

Lundeberg T (1984) Long-term results of vibratory stimulation as a pain relieving measure for chronic pain. Pain 20:13-23

Lundeberg T, Nordemar R, Ottoson D (1984) Pain alleviation by vibratory stimulation. Pain 20:25-44

Magnusson M, Enbom H, Johansson R, Wiklund J (1990) Significance of pressor input from the human feet in lateral postural control. The effect of hypothermia on galvanically induced body-sway. Acta Otolaryngol 110:321-327

Magnusson SP, Simonsen EB, Aagaard P, Boesen J, Johannsen F, Kjaer M (1997) Determinants of musculoskeletal flexibility: viscoelastic properties, cross-sectional area, EMG and stretch tolerance. Scand J Med Sci Sports 7:195-202

Malbut KE, Dinan S, Young A (2002) Aerobic training in the 'oldest old': the effect of 24 weeks of training. Age Ageing $31: 255-260$

Maloney-Hinds C, Petrofsky JS, Zimmerman G (2008) The effect of $30 \mathrm{~Hz}$ vs. $50 \mathrm{~Hz}$ passive vibration and duration of vibration on skin blood flow in the arm. Med Sci Monit 14:CR112-CR116

Mansfield NJ (2004) Hand-transmitted vibration standards. Human response to vibration. CRC press, Boca Raton, pp 169-186

Martin JH, Jessell TM (1991) Modality coding in the somatic sensory system. In: Kandel ER, Schwartz JH, Jessell TM (eds) Principles of neural science. Elsevier, Amsterdam

Matthews PB (1966) Reflex activation of the soleus muscle of the decerebrate cat by vibration. Nature 209:204-205

McCloskey DI, Matthews PB, Mitchell JH (1972) Absence of appreciable cardiovascular and respiratory responses to muscle vibration. J Appl Physiol 33:623

McCloskey DI, Ebeling P, Goodwin GM (1974) Estimation of weights and tensions and apparent involvement of a "sense of effort”. Exp Neurol 42:220-232
McGrath GJ, Matthews PB (1973) Evidence from the use of vibration during procaine nerve block that the spindle group II fibres contribute excitation to the tonic stretch reflex of the decerebrate cat. J Physiol (Lond) 235:371

Melnyk M, Kofler B, Faist M, Hodapp M, Gollhofer A (2008) Effect of a whole-body vibration session on knee stability. Int J Sports Med 29(10):839-844

Melzack R, Wall PD (1965) Pain mechanisms: a new theory. Science 150:971-979

Meyer-Waarden K (1985) Bioelektrische Signale und ihre Ableitverfahren [Bio-electric signals and their recording methods]. Schattauer, Stuttgart

Mian OS, Baltzopoulos V, Minetti AE, Narici MV (2007) The impact of physical training on locomotor function in older people. Sports Med 37:683-701

Mileva KN, Naleem AA, Biswas SK, Marwood S, Bowtell JL (2006) Acute effects of a vibration-like stimulus during knee extension exercise. Med Sci Sports Exerc 38:1317-1328

Milkiewicz M, Brown MD, Egginton S, Hudlicka O (2001) Association between shear stress, angiogenesis, and VEGF in skeletal muscles in vivo. Microcirculation 8:229-241

Moezy A, Olyaei G, Hadian M, Razi M, Faghihzadeh S (2008) A comparative study of whole body vibration training and conventional training on knee proprioception and postural stability after anterior cruciate ligament reconstruction. $\mathrm{Br} \mathrm{J}$ Sports Med 42:373-378

Moran K, McNamara B, Luo J (2007) Effect of vibration training in maximal effort (70\% 1RM) dynamic bicep curls. Med Sci Sports Exerc 39:526-533

Morse CI, Degens H, Seynnes OR, Maganaris CN, Jones DA (2008) The acute effect of stretching on the passive stiffness of the human gastrocnemius muscle tendon unit. J Physiol 586:97-106

Mosley JR, Lanyon LE (1998) Strain rate as a controlling influence on adaptive modeling in response to dynamic loading of the ulna in growing male rats. Bone 23:313

Mulder ER, Stegeman DF, Gerrits KH, Paalman MI, Rittweger J, Felsenberg D, de Haan A (2006) Strength, size and activation of knee extensors followed during 8 weeks of horizontal bed rest and the influence of a countermeasure. Eur J Appl Physiol 97:706-715

Mulder ER, Gerrits KH, Kleine BU, Rittweger J, Felsenberg D, de Haan A, Stegeman DF (2007a) High-density surface EMG study on the time course of central nervous and peripheral neuromuscular changes during 8 weeks of bed rest with or without resistive vibration exercise. J Electromyogr Kinesiol 19(2):208218

Mulder ER, Kuebler WM, Gerrits KH, Rittweger J, Felsenberg D, Stegeman DF, de Haan A (2007b) Knee extensor fatigability after bedrest for 8 weeks with and without countermeasure. Muscle Nerve 36:798-806

Murfee WL, Hammett LA, Evans C, Xie L, Squire M, Rubin C, Judex S, Skalak TC (2005) High-frequency, low-magnitude vibrations suppress the number of blood vessels per muscle fiber in mouse soleus muscle. J Appl Physiol 98:2376-2380

Nakamura H, Okazawa T, Nagase H, Yoshida M, Ariizumi M, Okada A (1996) Change in digital blood flow with simultaneous reduction in plasma endothelin induced by hand-arm vibration. Int Arch Occup Environ Health 68:115

Nazarov V, Spivak G (1985) Development of athlete's strength abilities by means of biomechanical stimulation method. Theory Prac Phys Culture 12:445-450

Necking LE, Lundborg G, Friden J (2002) Hand muscle weakness in long-term vibration exposure. J Hand Surg [Br] 27:520-525

Necking LE, Lundborg G, Lundstrom R, Thornell LE, Friden J (2004) Hand muscle pathology after long-term vibration exposure. J Hand Surg [Br] 29:431-437 
Nishihira Y, Iwasaki T, Hatta A, Wasaka T, Kaneda T, Kuroiwa K, Akiyama S, Kida T, Ryol KS (2002) Effect of whole body vibration stimulus and voluntary contraction on motorneuron pool. Jpn Soc Exerc Sports Physiol 10:83

O'Connor JA, Lanyon LE, MacFie H (1982) The influence of strain rate on adaptive bone remodelling. J Biomech 15:767

Oliveri DJ, Lynn K, Hong CZ (1989) Increased skin temperature after vibratory stimulation. Am J Phys Med Rehabil 68:81-85

Orr R, Raymond J, Fiatarone Singh M (2008) Efficacy of progressive resistance training on balance performance in older adults: a systematic review of randomized controlled trials. Sports Med 38:317-343

Otsuki T, Takanami Y, Aoi W, Kawai Y, Ichikawa H, Yoshikawa T (2008) Arterial stiffness acutely decreases after whole-body vibration in humans. Acta Physiol (Oxford, England) 194:189194

Oullier O, Kavounoudias A, Duclos C, Albert F, Roll JP, Roll R (2008) Countering postural posteffects following prolonged exposure to whole-body vibration: a sensorimotor treatment. Eur J Appl Physiol 105(2):235-245

Pavy-Le Traon A, Heer M, Narici MV, Rittweger J, Vernikos J (2007) From space to Earth: advances in human physiology from 20 years of bed rest studies (1986-2006). Eur J Appl Physiol 101:143-194

Pelmear PL (1974) Vibration white finger. Occup Health J Occup Health Nurses 26:307-310

Polonyova A, Hlavacka F (2001) Human postural responses to different frequency vibrations of lower leg muscles. Physiol Res 50:405-410

Pope MH, Broman H, Hansson T (1990) Factors affecting the dynamic response of the seated subject. J Spinal Disord 3:1351990

Pradko F, Lee RA, Greene JD (1967) Human vibration-response theory. In: Byars EF, Contini R, Roberts VL (eds) Biomechanics. American Society of Mechanical Engineers, New York, pp 205222

Priplata AA, Niemi JB, Harry JD, Lipsitz LA, Collins JJ (2003) Vibrating insoles and balance control in elderly people. Lancet 362:1123-1124

Quoniam C, Hay L, Roll JP, Harlay F (1995) Age effects on reflex and postural responses to propriomuscular inputs generated by tendon vibration. J Gerontol A Biol Sci Med Sci 50:B155-B165

Rees S, Murphy A, Watsford M (2007) Effects of vibration exercise on muscle performance and mobility in an older population. J Aging Phys Activity 15:367-381

Rees SS, Murphy AJ, Watsford ML (2008) Effects of whole body vibration on postural steadiness in an older population. J Sci Med Sport 12(4):440-444

Rehn B, Lidstrom J, Skoglund J, Lindstrom B (2007) Effects on leg muscular performance from whole-body vibration exercise: a systematic review. Scand J Med Sci Sports 17:2-11

Rennie MJ, Wackerhage H, Spangenburg EE, Booth FW (2004) Control of the size of the human muscle mass. Annu Rev Physiol 66:799-828

Ribot-Ciscar E, Vedel JP, Roll JP (1989) Vibration sensitivity of slowly and rapidly adapting cutaneous mechanoreceptors in the human foot and leg. Neurosci Lett 104:130

Ribot-Ciscar E, Roll JP, Tardy-Gervet MF, Harlay F (1996) Alteration of human cutaneous afferent discharges as the result of long- lasting vibration. J Appl Physiol 80:1708

Ribot-Ciscar E, Rossi-Durand C, Roll JP (1998) Muscle spindle activity following muscle tendon vibration in man. Neurosci Lett 258:147

Ribot-Ciscar E, Butler JE, Thomas CK (2003) Facilitation of triceps brachii muscle contraction by tendon vibration after chronic cervical spinal cord injury. J Appl Physiol 94:2358-2367
Rittweger J (2007) Physiological targets of artificial gravity: adaptive processes in bone. In: Clement G, Bukley A (eds) Artificial gravity. Springer, Berlin, pp 191-231

Rittweger J, Beller G, Felsenberg D (2000) Acute physiological effects of exhaustive whole-body vibration exercise in man. Clin Physiol 20:134

Rittweger J, Schiessl H, Felsenberg D (2001) Oxygen-uptake during whole body vibration exercise: comparison with squatting as a slow voluntary movement. Eur J Appl Physiol 86:169

Rittweger J, Ehrig J, Just K, Mutschelknauss M, Kirsch KA, Felsenberg D (2002a) Oxygen uptake in whole-body vibration exercise: influence of vibration frequency, amplitude, and external load. IntJ Sports Med 23:428

Rittweger J, Just K, Kautzsch K, Reeg P, Felsenberg D (2002b) Treatment of chronic lower back pain with lumbar extension and whole-body vibration exercise: a randomized controlled trial. Spine 27:1829

Rittweger J, Mutschelknauss M, Felsenberg D (2003) Acute changes in neuromuscular excitability after exhaustive whole body vibration exercise as compared to exhaustion by squatting exercise. Clin Physiol Funct Imaging 23:81

Rittweger J, Frost HM, Schiessl H, Ohshima H, Alkner B, Tesch P, Felsenberg D (2005) Muscle atrophy and bone loss after 90 days of bed rest and the effects of flywheel resistive exercise and pamidronate: results from the LTBR study. Bone 36:1019-1029

Rittweger J, Belavy D, Hunek P, Gast U, Boerst H, Feilcke B, Armbrecht G, Mulder E, Schubert H, Richardson C, de Haan A, Stegeman DF, Schiessl H, Felsenberg D (2006) Highly demanding resistive exercise program is tolerated during 56 days of strict bed rest. Int J Sports Med 27:553-559

Rittweger J, di Prampero PE, Maffulli N, Narici MV (2009a) Sprint and endurance power and ageing: an analysis of master athletic world records. Proc Biol Sci 276:683-689

Rittweger J, Moss AD, Colier W, Stewart CE, Degens H (2009b) Muscle tissue oxygenation and VEGF in Vo2-matched vibration and squatting exercise. Clin Physiol Funct Imaging accepted for publication

Roelants M, Delecluse C, Goris M, Verschueren S (2004a) Effects of 24 weeks of whole body vibration training on body composition and muscle strength in untrained females. Int $\mathrm{J}$ Sports Med 25:1-5

Roelants M, Delecluse C, Verschueren SM (2004b) Whole-bodyvibration training increases knee-extension strength and speed of movement in older women. J Am Geriatr Soc 52:901-908

Rogers DK, Bendrups AP, Lewis MM (1985) Disturbed proprioception following a period of muscle vibration in humans. Neurosci Lett 57:147-152

Roll JP, Vedel JP (1982) Kinaesthetic role of muscle afferents in man, studied by tendon vibration and microneurography. Exp Brain Res 47:177-190

Roll JP, Martin B, Gauthier GM, Mussa IF (1980) Effects of wholebody vibration on spinal reflexes in man. Aviat Space Environ Med 51:1227

Ronnestad BR (2004) Comparing the performance-enhancing effects of squats on a vibration platform with conventional squats in recreationally resistance-trained men. J Strength Cond Res 18:839-845

Rothmuller C, Cafarelli E (1995) Effect of vibration on antagonist muscle coactivation during progressive fatigue in humans. $\mathrm{J}$ Physiol 485(Pt 3):857

Rubin C, Turner AS, Bain S, Mallinckrodt C, McLeod K (2001a) Anabolism. Low mechanical signals strengthen long bones. Nature 412:603

Rubin C, Xu G, Judex S (2001b) The anabolic activity of bone tissue, suppressed by disuse, is normalized by brief exposure to 
extremely low-magnitude mechanical stimuli. FASEB J 15:2225-2229

Rubin CT, Sommerfeldt DW, Judex S, Qin Y (2001c) Inhibition of osteopenia by low magnitude, high-frequency mechanical stimuli. Drug Discov Today 6:848-858

Rubin C, Turner AS, Mallinckrodt C, Jerome C, McLeod K, Bain S (2002) Mechanical strain, induced noninvasively in the highfrequency domain, is anabolic to cancellous bone, but not cortical bone. Bone 30:445

Rubin C, Pope M, Fritton JC, Magnusson M, Hansson T, McLeod K (2003) Transmissibility of 15 -hertz to 35 -hertz vibrations to the human hip and lumbar spine: determining the physiologic feasibility of delivering low-level anabolic mechanical stimuli to skeletal regions at greatest risk of fracture because of osteoporosis. Spine 28:2621-2627

Rubin C, Recker R, Cullen D, Ryaby J, McCabe J, McLeod K (2004) Prevention of postmenopausal bone loss by a low-magnitude, high-frequency mechanical stimuli: a clinical trial assessing compliance, efficacy, and safety. J Bone Miner Res 19:343

Runge M, Rehfeld G, Resnicek E (2000) Balance training and exercise in geriatric patients. J Musculoskelet Neuronal Interact $1: 61$

Runge M, Rittweger J, Russo CR, Schiessl H, Felsenberg D (2004) Is muscle power output a key factor in the age-related decline in physical performance? A comparison of muscle cross section, chair-rising test and jumping power. Clin Physiol Funct Imaging 24:335-340

Russo CR, Lauretani F (2004) Author reply. Arch Phys Med Rehabil $85: 688$

Russo CR, Lauretani F, Bandinelli S, Bartali B, Cavazzini C, Guralnik JM, Ferrucci L (2003) High-frequency vibration training increases muscle power in postmenopausal women. Arch Phys Med Rehabil 84:1854

Salanova M, Schiffl G, Rittweger J, Felsenberg D, Blottner D (2008) Ryanodine receptor type-1 (RyR1) expression and protein S-nitrosylation pattern in human soleus myofibres following bed rest and exercise countermeasure. Histochem Cell Biol 130:105-118

Samuelson B, Jorfeldt L, Ahlborg B (1989) Influence of vibration on endurance of maximal isometric contraction. Clin Physiol 9:21-25

Sanders CE (1936) Cardiovascular and peripheral vascular diseases: treatment by a motorized oscillating bed. JAMA 106:916

Sato Y, Honda Y, Iwamoto J, Kanoko T, Satoh K (2005) Effect of folate and mecobalamin on hip fractures in patients with stroke: a randomized controlled trial. JAMA 293:1082

Schiessl H, Frost HM, Jee WS (1998) Estrogen and bone-muscle strength and mass relationships. Bone 22:1-6

Schlumberger A, Salin D, Schmidtbleicher D (2001) Strength training with superimposed vibrations. Sportverletz Sportschaden 15:1-7

Schonau E, Schwahn B, Rauch F (2002) The muscle-bone relationship: methods and management-perspectives in glycogen storage disease. Eur J Pediatr 161(Suppl 1):S50

Schönau E, Langensiepen S, Junghänel S, Semler O (2008) Neue Wege und Aufgaben in der Physiotherapie und Rehabilitation von bewegungsgestörten Kindern und Jugendlichen. Kinder Jugendmedizin 8:438-442

Schuhfried O, Mittermaier C, Jovanovic T, Pieber K, PaternostroSluga T (2005) Effects of whole-body vibration in patients with multiple sclerosis: a pilot study. Clin Rehabil 19:834-842

Seidel H (1988) Myoelectric reactions to ultra-low frequency and low-frequency whole body vibration. Eur J Appl Physiol Occup Physiol 57:558-562

Semler O, Fricke O, Vezyroglou K, Stark C, Schoenau E (2007) Preliminary results on the mobility after whole body vibration in immobilized children and adolescents. J Musculoskelet Neuronal Interact 7:77-81
Semler O, Fricke O, Vezyroglou K, Stark C, Stabrey A, Schoenau E (2008) Results of a prospective pilot trial on mobility after whole body vibration in children and adolescents with osteogenesis imperfecta. Clin Rehabil 22:387-394

Shackelford LC, LeBlanc AD, Driscoll TB, Evans HJ, Rianon NJ, Smith SM, Spector E, Feeback DL, Lai D (2004) Resistance exercise as a countermeasure to disuse-induced bone loss. J Appl Physiol 97:119

Sherrington CS (1906) The integrative action of the nervous system. Yale University Press, New Haven

Shinohara M, Moritz CT, Pascoe MA, Enoka RM (2005) Prolonged muscle vibration increases stretch reflex amplitude, motor unit discharge rate, and force fluctuations in a hand muscle. J Appl Physiol 99:1835-1842

Siggelkow S, Kossev A, Schubert M, Kappels HH, Wolf W, Dengler R (1999) Modulation of motor evoked potentials by muscle vibration: the role of vibration frequency. Muscle Nerve 22:1544-1548

Spitzenpfeil P, Mester J (1997) Vibrationsbelastungen beim alpinen Skilauf. Sportorthopädie, Sporttraumatologie, p 209

Stoyneva Z, Lyapina M, Tzvetkov D, Vodenicharov E (2003) Current pathophysiological views on vibration-induced Raynaud's phenomenon. Cardiovasc Res 57:615-624

Suhr F, Brixius K, de Marees M, Bolck B, Kleinoder H, Achtzehn S, Bloch W, Mester J (2007) Effects of short-term vibration and hypoxia during high-intensity cycling exercise on circulating levels of angiogenic regulators in humans. J Appl Physiol 103:474-483

Tardy-Gervet MF, Guieu R, Ribot-Ciscar E, Roll JP (1993) Transcutaneous mechanical vibrations: analgesic effect and antinociceptive mechanisms. Rev Neurol (Paris) 149:177

Taube W, Gruber M, Gollhofer A (2008) Spinal and supraspinal adaptations associated with balance training and their functional relevance. Acta physiologica (Oxford, England) 193:101-116

Taylor W, Ogston SA, Brammer AJ (1986) A clinical assessment of seventy-eight cases of hand-arm vibration syndrome. Scand J Work Environ Health 12:265-268

Tihanyi TK, Horvath M, Fazekas G, Hortobagyi T, Tihanyi J (2007) One session of whole body vibration increases voluntary muscle strength transiently in patients with stroke. Clin Rehabil 21:782793

Torvinen S, Kannu P, Sievanen H, Jarvinen TA, Pasanen M, Kontulainen S, Jarvinen TL, Jarvinen M, Oja P, Vuori I (2002a) Effect of a vibration exposure on muscular performance and body balance. Randomized cross-over study. Clin Physiol Funct Imaging 22:145

Torvinen S, Kannus P, Sievanen H, Jarvinen TA, Pasanen M, Kontulainen S, Jarvinen TL, Jarvinen M, Oja P, Vuori I (2002b) Effect of four-month vertical whole body vibration on performance and balance. Med Sci Sports Exerc 34:1523

Torvinen S, Kannus P, Sievanen H, Jarvinen TA, Pasanen M, Kontulainen S, Nenonen A, Jarvinen TL, Paakkala T, Jarvinen M, Vuori I (2003) Effect of 8-month vertical whole body vibration on bone, muscle performance, and body balance: a randomized controlled study. J Bone MinerRes 18:876

Turbanski S, Haas CT, Schmidtbleicher D, Friedrich A, Duisberg P (2005) Effects of random whole-body vibration on postural control in Parkinson's disease. Res Sports Med (Print) 13:243-256

Turner CH, Forwood MR, Otter MW (1994) Mechanotransduction in bone: do bone cells act as sensors of fluid flow? FASEB J 8:875

van Boxtel A (1986) Differential effects of low-frequency depression, vibration-induced inhibition, and posttetanic potentiation on H-reflex and tendon jerks in the human soleus muscle. J Neurophysiol 55:551

van den Tillaar R (2006) Will whole-body vibration training help increase the range of motion of the hamstrings? J Strength Cond Res 20:192-196 
van Duijnhoven NT, Bleeker MW, de Groot PC, Thijssen DH, Felsenberg D, Rittweger J, Hopman MT (2008) The effect of bed rest and an exercise countermeasure on leg venous function. Eur J Appl Physiol 104:991-998

van Nes IJ, Geurts AC, Hendricks HT, Duysens J (2004) Short-term effects of whole-body vibration on postural control in unilateral chronic stroke patients: preliminary evidence. Am J Phys Med Rehabil 83:867-873

Verschueren SM, Roelants M, Delecluse C, Swinnen S, Vanderschueren D, Boonen S (2004) Effect of 6-month whole body vibration training on hip density, muscle strength, and postural control in postmenopausal women: a randomized controlled pilot study. J Bone Miner Res 19:352

Viru A (1992) Plasma hormones and physical exercise. Int J Sports Med 13:201-209

Wakeling JM, Nigg BM, Rozitis AI (2002) Muscle activity damps the soft tissue resonance that occurs in response to pulsed and continuous vibrations. J Appl Physiol 93:1093-1103

Wang Y, Kerrick WG (2002) The off rate of $\mathrm{Ca}(2+)$ from troponin C is regulated by force-generating cross bridges in skeletal muscle. J Appl Physiol 92:2409-2418

Ward K, Alsop C, Caulton J, Rubin C, Adams J, Mughal Z (2004) Low magnitude mechanical loading is osteogenic in children with disabling conditions. J Bone Miner Res 19:360

Watanabe Y, Ohshima H, Mizuno K, Sekiguchi C, Fukunaga M, Kohri K, Rittweger J, Felsenberg D, Matsumoto T, Nakamura T (2004) Intravenous pamidronate prevents femoral bone loss and renal stone formation during 90-day bed rest. J Bone Miner Res 19:1771

Weerakkody NS, Whitehead NP, Canny BJ, Gregory JE, Proske U (2001) Large-fiber mechanoreceptors contribute to muscle soreness after eccentric exercise. J Pain 2:209-219

Weerakkody NS, Percival P, Hickey MW, Morgan DL, Gregory JE, Canny BJ, Proske U (2003) Effects of local pressure and vibration on muscle pain from eccentric exercise and hypertonic saline. Pain 105:425-435
Welsh CL (1980) The effect of vibration on digital blood flow. The $\mathrm{Br}$ J Surg 67:708-710

Whedon GD, Deitrick JE, Shorr E (1949) Modification of the effects of immobilization upon metabolic and physiologic functions of normal men by the use of an oscillating bed. Am J Med 6(6):684-711

Wierzbicka MM, Gilhodes JC, Roll JP (1998) Vibration-induced postural posteffects. J Neurophysiol 79:143-150

Wong AM, Lan C (2008) Tai Chi and balance control. Med Sport Sci 52:115-123

Wong RC, Fairley JA, Ellis CN (1984) Dermographism: a review. J Am Acad Dermatol 11:643

Xie L, Jacobson JM, Choi ES, Busa B, Donahue LR, Miller LM, Rubin CT, Judex S (2006) Low-level mechanical vibrations can influence bone resorption and bone formation in the growing skeleton. Bone 39:1059-1066

Xie L, Rubin C, Judex S (2008) Enhancement of the adolescent murine musculoskeletal system using low-level mechanical vibrations. J Appl Physiol 104:1056-1062

Yamada E, Kusaka T, Miyamoto K, Tanaka S, Morita S, Tanaka S, Tsuji S, Mori S, Norimatsu H, Itoh S (2005) Vastus lateralis oxygenation and blood volume measured by near-infrared spectroscopy during whole body vibration. Clin Physiol Funct Imaging 25:203-208

Yue Z, Mester J (2002) A model analysis of internal loads, energetics, and effects of wobbling mass during the whole-body vibration. J Biomech 35:639

Zange J, Haller T, Muller K, Liphardt AM, Mester J (2008a) Energy metabolism in human calf muscle performing isometric plantar flexion superimposed by $20-\mathrm{Hz}$ vibration. Eur J Appl Physiol 105(2):265-270

Zange J, Mester J, Heer M, Kluge G, Liphardt AM (2008b) 20-Hz whole body vibration training fails to counteract the decrease in leg muscle volume caused by 14 days of 6 degrees head down tilt bed rest. Eur J Appl Physiol 105:271-277 